\title{
LEVITIN-POLYAK WELL-POSEDNESS OF COMPLETELY GENERALIZED MIXED VARIATIONAL INEQUALITIES IN REFLEXIVE BANACH SPACES
}

\author{
LU-CHUAN CENG AND CHING-FENG WEN
}

\begin{abstract}
Let $X$ be a real reflexive Banach space. In this paper, we first introduce the concept of Levitin-Polyak well-posedness of a completely generalized mixed variational inequality in $X$, and establish some characterizations of its Levitin-Polyak well-posedness. Under suitable conditions, we prove that the Levitin-Polyak well-posedness of a completely generalized mixed variational inequality is equivalent both to the Levitin-Polyak well-posedness of a corresponding inclusion problem and to the Levitin-Polyak wellposedness of a corresponding fixed point problem. We also derive some conditions under which a completely generalized mixed variational inequality in $X$ is Levitin-Polyak well-posed. Our results improve, extend and develop the early and recent ones in the literature.
\end{abstract}

\section{Introduction}

In 1966, Tykhonov [1] first introduced the concept of Tykhonov well-posedness of a minimization problem. More precisely, this concept consists of the existence and uniqueness of minimizers, and the convergence of every minimizing sequence to the unique minimizer. In many practical situations, there are more than one minimizer for a minimization problem. In a natural way, the concept of Tykhonov well-posedness in the generalized sense was introduced, which means the existence of minimizers and the convergence of some subsequence of every minimizing sequence to a minimizer. Without question, the concept of well-posedness is motivated by the numerical methods producing optimizing sequences. Because it plays an important role in the study of optimization problems, various concepts of Received July 30, 2016, accepted October 4, 2016. 2010 Mathematics Subject Classification. 49J40, 49K40, 90C31.

Key words and phrases. Completely generalized mixed variational inequality, inclusion problem, fixed point problem; Levitin-Polyak well-posedness.

This research was partially supported by the Innovation Program of Shanghai Municipal Education Commission (15ZZ068), Ph.D. Program Foundation of Ministry of Education of China (20123127110002) and Program for Outstanding Academic Leaders in Shanghai City (15XD1503100). This research was partially supported by the grant MOST 105-2115-M-037-001. Corresponding author: Ching-Feng Wen. 
well-posedness have been introduced and studied widely for minimization problems in past decades. A great deal of effort has gone into those concepts; see, e.g., [2]-[4] and the references therein.

The Tykhonov well-posedness of a constrained minimization problem requires that every minimizing sequence should lie in the constraint set. It is well known that in many practical situations, the minimizing sequence produced by a numerical optimization method usually fails to be feasible but gets closer and closer to the constraint set. Such a sequence is called a generalized minimizing sequence for constrained minimization problems. Taking into account this case, Levitin and Polyak [5] strengthened the concept of Tykhonov well-posedness by requiring the existence and uniqueness of minimizers, and the convergence of every generalized minimizing sequence to the unique minimizer, which is called Levitin and Polyak (for short, LP) well-posedness. There have been a large number of results involving Tykhonov well-posedness, LP well-posedness and their generalizations for minimization problems. For details, we refer the readers to $[1,2,3,5,6,7]$.

In 2008, Fang, Huang and Yao [11] considered and studied the well-posedness of a mixed variational inequality in a real Hilbert space $H$, which includes as a special case the classical variational inequality, and derived some results for the well-posedness of such a mixed variational inequality, the corresponding inclusion problem and the corresponding fixed-point problem. Subsequently, Ceng and Yao [9] extended the concept of well-posedness to a generalized mixed variational inequality in $H$, which includes as a special case the mixed variational inequality, and gave some characterizations of its well-posedness. Under suitable conditions, the authors [9] proved that the well-posedness of the generalized mixed variational inequality is equivalent both to the well-posedness of the corresponding inclusion problem and to the corresponding fixed-point problem, and derived some conditions under which the generalized mixed variational inequality is well-posed. Recently, some authors made the further extension and development on the concept of well-posedness; see, e.g., [20]-[24] and the references therein.

On the other hand, Hu and Huang [14] considered the Levitin-Polyak well-posedness of a general variational inequality in $\mathbf{R}^{n}$. They derived some characterizations of the LevitinPolyak well-posedness by considering the size of Levitin-Polyak approximating solution sets of general variational inequalities. They also proved that the Levitin-Polyak well-posedness of a general variational inequality is closely related to the Levitin-Polyak well-posedness of a minimization problem and a fixed point problem. Finally, they proved that under suitable conditions, the Levitin-Polyak well-posedness of a general variational inequality is equivalent to the uniqueness and existence of its solutions.

Let $X$ be a real reflexive Banach space. In 2012, Li and Xia [19] extended the notion of Levitin-Polyak well-posedness to a generalized mixed variational inequality in $X$, and gave 
some characterizations of its Levitin-Polyak well-posedness. Under suitable conditions, they proved that the Levitin-Polyak well-posedness of a generalized mixed variational inequality is closely related to the Levitin-Polyak well-posedness of a corresponding inclusion problem and a corresponding fixed point problem, and derived some conditions under which a generalized mixed variational inequality is Levitin-Polyak well-posed. However, there is no result for the Levitin-Polyak well-posedness of a completely generalized mixed variational inequality. Therefore, it is worth studying implementable results for the Levitin-Polyak wellposedness of a completely generalized mixed variational inequality.

Motivated and inspired by the research work going on this field, we extend the notion of Levitin-Polyak well-posedness to a completely generalized mixed variational inequality in a real reflexive Banach space $X$, and give some characterizations of its Levitin-Polyak wellposedness. Under suitable conditions, we prove the Levitin-Polyak well-posedness of a completely generalized mixed variational inequality is closely related to the Levitin-Polyak wellposedness of a corresponding inclusion problem and a corresponding fixed point problem. Finally, we derive some conditions under which a completely generalized mixed variational inequality is Levitin-Polyak well-posed. Our results improve, extend and develop the early and recent ones announced by some others, e.g., Ceng and Yao [9] and Li and Xia [19].

\section{Preliminaries}

Let $X$ be a real reflexive Banach space with its dual $X^{*}$ and $K$ be a nonempty, closed and convex subset of $X$. Let $g: X \rightarrow X$ be a single-valued mapping, $N: X^{*} \times X^{*} \rightarrow X^{*}$ be a singlevalued mapping, and $F, E: X \rightarrow 2^{X^{*}}$ be two set-valued mappings. Let $\phi: X \times X \rightarrow \mathbf{R} \cup\{+\infty\}$ be such that for each $x \in X, \phi(\cdot, x)$ is a proper, convex and lower semicontinuous functional. For each $x \in X$, we denote by $\operatorname{dom} \phi(\cdot, x)$ the domain of $\phi(\cdot, x)$, i.e.,

$$
\operatorname{dom} \phi(\cdot, x)=\{y \in X: \phi(y, x)<+\infty\}
$$

In this paper we always assume that $g(X) \cap \operatorname{dom} \phi(\cdot, x) \cap K \neq \varnothing$ for each $x \in X$. Consider the following completely generalized mixed variational inequality associated with $(N(F, E), g, \phi, K)$ :

$\operatorname{CGMVI}(N(F, E), g, \phi, K):$ find $x \in K$ such that $g(x) \in K$ and

$$
\langle N(u, v), g(x)-y\rangle+\phi(g(x), x)-\phi(y, x) \leq 0, \forall y \in K,
$$

for some $u \in F(x)$ and $v \in E(x)$.

It is easy to see that the CGMVI $(N(F, E), g, \phi, K)$ is equivalent to the following inclusion problem associated with $N(F, E)+\partial\left(\phi+\delta_{K}\right) \circ g$ :

$$
\begin{aligned}
& \operatorname{IP}\left(N(F, E)+\partial\left(\phi+\delta_{K}\right) \circ g, K\right) \text { : find } x \in K \text { such that } g(x) \in K \text { and } \\
& \qquad 0 \in N(F(x), E(x))+\partial\left(\phi(\cdot, x)+\delta_{K}\right)(g(x)),
\end{aligned}
$$


where $\delta_{K}$ denotes the indicator function associated with $K$ (i.e., $\delta_{K}(x)=0$ if $x \in K$ and $+\infty$ otherwise) and for a fixed $x \in X, \partial\left(\phi(\cdot, x)+\delta_{K}\right)(g(x))$ denotes the subdifferential of the convex function $\phi(\cdot, x)+\delta_{k}$ at $g(x)$. It is clear that $\operatorname{CGMVI}(N(F, E), g, \phi, K)$ includes as a special case the following generalized mixed variational inequality associated with $(F, \phi, K)$ (considered in [19]):

$$
\begin{gathered}
\operatorname{GMVI}(F, \phi, K) \text { : find } x \in K \text { such that for some } u \in F(x), \\
\langle u, x-y\rangle+\phi(x)-\phi(y) \leq 0, \forall y \in K .
\end{gathered}
$$

Moreover, $\operatorname{IP}\left(N(F, E)+\partial\left(\phi+\delta_{K}\right) \circ g, K\right)$ obviously includes as a special case the following inclusion problem associated with $F+\partial\left(\phi+\delta_{K}\right)$ (considered in [19]):

$$
\operatorname{IP}\left(F+\partial\left(\phi+\delta_{K}\right), K\right): \text { find } x \in K \text { such that } 0 \in F(x)+\partial\left(\phi+\delta_{K}\right)(x) .
$$

It is not hard to find that there holds the following:

Proposition 2.1. Let $K$ be a nonempty, closed and convex subset of $X$. Let $g: X \rightarrow X$ be a single-valued mapping, $N: X^{*} \times X^{*} \rightarrow X^{*}$ be a single-valued mapping, and $F, E: X \rightarrow 2^{X^{*}}$ be two nonempty set-valued mappings. Let $\phi: X \times X \rightarrow \mathbf{R} \cup\{+\infty\}$ be such that for each $x \in X, \phi(\cdot, x)$ is a proper, convex and lower semicontinuous functional. Then the following conclusions are equivalent:

(i) $x$ solves $\operatorname{CGMVI}(N(F, E), g, \phi, K)$;

(ii) $x$ solves $\operatorname{IP}\left(N(F, E)+\partial\left(\phi+\delta_{K}\right) \circ g, K\right)$.

Definition 2.1. Let $A, B$ be nonempty subsets of $X$. The Hausdorff metric $\mathscr{H}(\cdot, \cdot)$ between $A$ and $B$ is defined by

$$
\mathscr{H}(A, B)=\max \{e(A, B), e(B, A)\},
$$

where $e(A, B)=\sup _{a \in A} d(a, B)$ with $d(a, B)=\inf _{b \in B}\|a-b\|$.

Lemma 2.1 (Nadler's Theorem [7]). Let $(X,\|\cdot\|)$ be a normed vector space and $\mathscr{H}(\cdot, \cdot)$ be the Hausdorff metric on the collection $C B(X)$ of all nonempty, closed and bounded subsets of $X$, induced by a metric d in terms of $d(u, v)=\|u-v\|$, which is defined by $\mathscr{H}(U, V)=\max \{e(U, V)$, $e(V, U)\}$ for $U$ and $V$ in $C B(X)$ where $e(U, V)=\sup _{x \in U} d(x, V)$ with $d(x, V)=\inf _{y \in V}\|x-y\|$. If $U$ and $V$ lie in $C B(X)$, then for any $\epsilon>0$ and any $u \in U$, there exists $v \in V$ such that $\|u-v\| \leq$ $(1+\epsilon) \mathscr{H}(U, V)$. In particular, whenever $U$ and $V$ are compact subsets in $X$, one has $\|u-v\| \leq$ $\mathscr{H}(U, V)$.

Definition 2.2. A single-valued mapping $N: X^{*} \times X^{*} \rightarrow X^{*}$ is called mixed Lipschitz continuous with respect to the first and second arguments if there exists a pair of constants $\zeta, \xi>0$ such that

$$
\left\|N\left(u_{1}, v_{1}\right)-N\left(u_{2}, v_{2}\right)\right\| \leq \zeta\left\|u_{1}-u_{2}\right\|+\xi\left\|v_{1}-v_{2}\right\|, \quad \forall\left(u_{i}, v_{i}\right) \in X^{*} \times X^{*}, i=1,2 .
$$


Definition 2.3. Let $F: X \rightarrow C B\left(X^{*}\right)$ be a set-valued mapping. Then,

(i) $F$ is called $\mathscr{H}$-continuous at a point $x_{0} \in X$, if for any $\epsilon>0$ there exists $\delta>0$ such that for all $x \in X$ with $\left\|x-x_{0}\right\|<\delta$, one has $\mathscr{H}\left(F(x), F\left(x_{0}\right)\right)<\epsilon$. If $F$ is $\mathscr{H}$-continuous at each point $x \in X$, then $F$ is called $\mathscr{H}$-continuous.

(ii) $F$ is called $\mathscr{H}$-uniformly continuous [9], if for any $\epsilon>0$ there exists $\delta>0$ such that for all $x, y \in X$ with $\|x-y\|<\delta$, one has $\mathscr{H}(F(x), F(y))<\epsilon$.

Definition 2.4. Let $X$ and $Y$ be two topological spaces and $x \in X$. A set-valued mapping $F: X \rightarrow 2^{Y}$ is said to be upper semicontinuous (in short, u.s.c) at $x$, if for any neighborhood $V$ of $F(x)$, there exists a neighborhood $U$ of $x$ such that $F(y) \subset V, \forall y \in U$. If $F$ is u.s.c at each point of $X$, we say that $F$ is u.s.c on $X$.

Definition 2.5 ([15]). Let $A$ be a nonempty subset of $X$. The measure of noncompactness $\mu$ of the set $A$ is defined by

$$
\mu(A)=\inf \left\{\epsilon>0: A \subset \bigcup_{i=1}^{n} A_{i}, \operatorname{diam} A_{i}<\epsilon, i=1,2, \ldots, n\right\},
$$

where diam means the diameter of a set.

\section{Levitin-Polyak Well-Posedness of CGMVI $(N(F, E), g, \phi, K)$}

In this section, we extend the concept of Levitin-Polyak well-posedness to the completely generalized mixed variational inequality and establish its metric characterizations. In the sequel, we always denote by $\rightarrow$ and $\rightarrow$ the strong convergence and weak convergence, respectively. Let $\alpha \geq 0$ be a given number, and let $X, K, N, F, E, g, \phi$ be defined as in the previous section.

Definition 3.1. A sequence $\left\{x_{n}\right\} \subset K$ is called a LP $\alpha$-approximating sequence for $\operatorname{CGMVI}(N(F, E), g, \phi, K)$, if there exists $w_{n} \in X$ with $w_{n} \rightarrow 0$ and $0<\epsilon_{n} \rightarrow 0$ such that $g\left(x_{n}\right)+$ $w_{n} \in K$ for all $n \geq 1$, and there exist $u_{n} \in F\left(x_{n}\right)$ and $v_{n} \in E\left(x_{n}\right)$ such that

$$
g\left(x_{n}\right) \in \operatorname{dom} \phi\left(\cdot, x_{n}\right), \quad\left\langle N\left(u_{n}, v_{n}\right), g\left(x_{n}\right)-y\right\rangle+\phi\left(g\left(x_{n}\right), x_{n}\right)-\phi\left(y, x_{n}\right) \leq \frac{\alpha}{2}\left\|g\left(x_{n}\right)-y\right\|^{2}+\epsilon_{n}
$$

for all $y \in K$ and $n \geq 1$. If $\alpha_{1}>\alpha_{2} \geq 0$, then every LP $\alpha_{2}$-approximating sequence is LP $\alpha_{1^{-}}$ approximating. When $\alpha=0$, we say that $\left\{x_{n}\right\}$ is a LP approximating sequence for $\operatorname{CGMVI}(N(F, E), g, \phi, K)$.

Definition 3.2. We say that CGMVI $(N(F, E), g, \phi, K)$ is strongly (resp. weakly) LP $\alpha$-well-posed if CGMVI $(N(F, E), g, \phi, K)$ has a unique solution and every LP $\alpha$-approximating sequence converges strongly (resp. weakly) to the unique solution. In the sequel, strong (resp. weak) LP 0well-posedness is always known as strong (resp. weak) LP well-posedness. If $\alpha_{1}>\alpha_{2} \geq 0$, then strong (resp. weak) LP $\alpha_{1}$-well-posedness implies strong (resp. weak) LP $\alpha_{2}$-well-posedness. 
Definition 3.3. We say that CGMVI $(N(F, E), g, \phi, K)$ is strongly (resp. weakly) LP $\alpha$-well-posed in the generalized sense if CGMVI $(N(F, E), g, \phi, K)$ has nonempty solution set $S$ and every LP $\alpha$-approximating sequence has a subsequence which converges strongly (resp. weakly) to some point of $S$. In the sequel, strong (resp. weak) LP 0-well-posedness in the generalized sense is always known as strong (resp. weak) LP well-posedness in the generalized sense. If $\alpha_{1}>\alpha_{2} \geq 0$, then strong (resp. weak) LP $\alpha_{1}$-well-posedness in the generalized sense implies strong (resp. weak) LP $\alpha_{2}$-well-posedness in the generalized sense.

Remark 3.1. When CGMVI $(N(F, E), g, \phi, K)=\operatorname{GMVI}(F, \phi, K)$, Definitions 3.1, 3.2 and 3.3 reduce to the Definitions 3.1, 3.2 and 3.3 in [19], respectively. When $X$ is a real Hilbert space, $K=X$ and $w_{n} \equiv 0$, Definitions 3.2 and 3.3 in [19] reduce to the Definitions 3.2 and 3.3 in [11], respectively. When $X=\mathbf{R}^{n}, \alpha=0, \phi=\delta_{K}$ and $F$ is single-valued, Definitions 3.2 and 3.3 in [19] reduce to the Definitions 3.3 and 3.4 in [14], respectively.

To derive the metric characterizations of LP $\alpha$-well-posedness, we consider the following LP $\alpha$-approximating solution set of $\operatorname{CGMVI}(N(F, E), g, \phi, K)$ :

$$
\begin{aligned}
\Omega_{\alpha}(\epsilon)= & \{x \in X: g(x) \in \operatorname{dom} \phi(\cdot, x), d(g(x), K) \leq \epsilon \text {, and } \\
& \text { there exists } u \in F(x) \text { and } v \in E(x) \text { such that } \forall y \in K, \\
& \left.\langle N(u, v), g(x)-y\rangle+\phi(g(x), x)-\phi(y, x) \leq \frac{\alpha}{2}\|g(x)-y\|^{2}+\epsilon\right\}, \quad \forall \epsilon \geq 0 .
\end{aligned}
$$

Theorem 3.1. Let $K$ be a nonempty, closed and convex subset of $X$. Let $F, E: X \rightarrow 2^{X^{*}}$ be nonempty compact-valued mappings which both are $\mathscr{H}$-continuous. Let $g: X \rightarrow X$ be a continuous mapping and $N: X^{*} \times X^{*} \rightarrow X^{*}$ be mixed Lipschitz continuous with respect to the first and second arguments. Assume that $\phi: X \times X \rightarrow \mathbf{R} \cup\{+\infty\}$ satisfies the conditions:

(C1) $\phi$ is proper, convex and lower semicontinuous in the first argument;

(C2) $\phi$ is upper semicontinuous in the second argument;

(C3) $\liminf _{n \rightarrow \infty} \inf _{y \in \operatorname{dom} \phi\left(\cdot, x_{n}\right)}\left(\phi\left(y, x_{n}\right)-\phi(y, \bar{x})\right) \geq 0, \forall\left\{x_{n}\right\} \subset K: x_{n} \rightarrow \bar{x}(n \rightarrow \infty)$.

Then CGMVI $(N(F, E), g, \phi, K)$ is strongly LP $\alpha$-well-posed if and only if

$$
\Omega_{\alpha}(\epsilon) \neq \varnothing, \quad \forall \epsilon>0 \text { and } \operatorname{diam}\left(\Omega_{\alpha}(\epsilon)\right) \rightarrow 0 \text { as } \epsilon \rightarrow 0 .
$$

Proof. Suppose that CGMVI $(N(F, E), g, \phi, K)$ is strongly LP $\alpha$-well-posed and $x^{*} \in K$ is the unique solution of $\operatorname{CGMVI}(N(F, E), g, \phi, K)$. It is obvious that $x^{*} \in \Omega_{\alpha}(\epsilon)$. If $\operatorname{diam}\left(\Omega_{\alpha}(\epsilon)\right) \nrightarrow 0$ as $\epsilon \rightarrow 0$, then there exist constant $l>0$ and sequences $\left\{\epsilon_{n}\right\} \subset \mathbf{R}^{+}$with $\epsilon_{n} \rightarrow 0$, and $\left\{x_{n}^{(1)}\right\},\left\{x_{n}^{(2)}\right\}$ with $x_{n}^{(1)}, x_{n}^{(2)} \in \Omega_{\alpha}\left(\epsilon_{n}\right)$ such that

$$
\left\|x_{n}^{(1)}-x_{n}^{(2)}\right\|>l, \quad \forall n \geq 1 .
$$


Since $x_{n}^{(1)}, x_{n}^{(2)} \in \Omega_{\alpha}\left(\epsilon_{n}\right)$, for $x_{n}^{(1)}$ we have

$$
d\left(g\left(x_{n}^{(1)}\right), K\right) \leq \epsilon_{n}<\epsilon_{n}+\frac{1}{n}
$$

and there exists $u_{n} \in F\left(x_{n}^{(1)}\right)$ and $v_{n} \in E\left(x_{n}^{(1)}\right)$ such that

$$
\left\langle N\left(u_{n}, v_{n}\right), g\left(x_{n}^{(1)}\right)-y\right\rangle+\phi\left(g\left(x_{n}^{(1)}\right), x_{n}^{(1)}\right)-\phi\left(y, x_{n}^{(1)}\right) \leq \frac{\alpha}{2}\left\|g\left(x_{n}^{(1)}\right)-y\right\|^{2}+\epsilon_{n}, \quad \forall y \in K .
$$

Since $K$ is closed and convex, then there exists $\bar{x}_{n}^{(1)} \in K$ such that $\left\|g\left(x_{n}^{(1)}\right)-\bar{x}_{n}^{(1)}\right\|<\epsilon_{n}+\frac{1}{n}$. Putting $w_{n}=\bar{x}_{n}^{(1)}-g\left(x_{n}^{(1)}\right)$, we have $w_{n}+g\left(x_{n}^{(1)}\right)=\bar{x}_{n}^{(1)} \in K$ and $\left\|w_{n}\right\|=\left\|g\left(x_{n}^{(1)}\right)-\bar{x}_{n}^{(1)}\right\| \rightarrow 0$. This implies that $w_{n} \rightarrow 0$. Thus, $\left\{x_{n}^{(1)}\right\}$ is a LP approximating sequence for $\operatorname{CGMVI}(N(F, E), g, \phi, K)$. By the similar argument, we obtain that $\left\{x_{n}^{(2)}\right\}$ is a LP approximating sequence for $\operatorname{CGMVI}(N(F, E), g, \phi, K)$. So they have to converge strongly to the unique solution of $\operatorname{CGMVI}(N(F, E), g, \phi, K)$, a contradiction to (3.2).

Conversely, suppose that the conclusion (3.1) holds. Let $\left\{x_{n}\right\} \subset K$ be a LP $\alpha$-approximating sequence for CGMVI $(N(F, E), g, \phi, K)$. Then there exists $w_{n} \in X$ with $w_{n} \rightarrow 0$ and $0<\epsilon_{n}^{\prime} \rightarrow 0$ such that $g\left(x_{n}\right)+w_{n} \in K$ for all $n \geq 1$, and there exist $u_{n} \in F\left(x_{n}\right)$ and $v_{n} \in E\left(x_{n}\right)$ such that

$$
g\left(x_{n}\right) \in \operatorname{dom} \phi\left(\cdot, x_{n}\right), \quad\left\langle N\left(u_{n}, v_{n}\right), g\left(x_{n}\right)-y\right\rangle+\phi\left(g\left(x_{n}\right), x_{n}\right)-\phi\left(y, x_{n}\right) \leq \frac{\alpha}{2}\left\|g\left(x_{n}\right)-y\right\|^{2}+\epsilon_{n}^{\prime}
$$

for all $y \in K$ and $n \geq 1$. Since $g\left(x_{n}\right)+w_{n} \in K$, then there exists $k_{n} \in K$ such that $g\left(x_{n}\right)+w_{n}=k_{n}$. It is easy to see that $d\left(g\left(x_{n}\right), K\right) \leq\left\|g\left(x_{n}\right)-k_{n}\right\|=\left\|w_{n}\right\| \rightarrow 0$. Set $\epsilon_{n}=\max \left\{\epsilon_{n}^{\prime},\left\|w_{n}\right\|\right\}$, it follows that $x_{n} \in \Omega_{\alpha}\left(\epsilon_{n}\right)$. From (3.1), we deduce that $\left\{x_{n}\right\}$ is a Cauchy sequence and so it converges strongly to a point $\bar{x} \in K$. Since $g\left(x_{n}\right)+w_{n} \in K, w_{n} \rightarrow 0$ and $g$ is continuous, we know that $g(\bar{x}) \in K$. So, it follows from (3.3) and conditions (C1)-(C3) that

$$
\liminf _{n \rightarrow \infty}\left(\phi\left(g\left(x_{n}\right), x_{n}\right)-\phi\left(g\left(x_{n}\right), \bar{x}\right)\right) \geq \liminf _{n \rightarrow \infty} \inf _{y \in \operatorname{dom} \phi\left(\cdot, x_{n}\right)}\left(\phi\left(y, x_{n}\right)-\phi(y, \bar{x})\right) \geq 0,
$$

and

$$
\begin{aligned}
\liminf _{n \rightarrow \infty}\left\langle N\left(u_{n}, v_{n}\right), g\left(x_{n}\right)-y\right\rangle+\phi(g(\bar{x}), \bar{x})-\phi(y, \bar{x}) \\
\leq \quad \liminf _{n \rightarrow \infty}\left\langle N\left(u_{n}, v_{n}\right), g\left(x_{n}\right)-y\right\rangle+\liminf _{n \rightarrow \infty} \phi\left(g\left(x_{n}\right), \bar{x}\right)+\liminf _{n \rightarrow \infty}\left(\phi\left(g\left(x_{n}\right), x_{n}\right)-\phi\left(g\left(x_{n}\right), \bar{x}\right)\right) \\
\quad+\liminf _{n \rightarrow \infty}\left(-\phi\left(y, x_{n}\right)\right) \\
\leq \liminf _{n \rightarrow \infty}\left\{\left\langle N\left(u_{n}, v_{n}\right), g\left(x_{n}\right)-y\right\rangle+\phi\left(g\left(x_{n}\right), \bar{x}\right)+\phi\left(g\left(x_{n}\right), x_{n}\right)-\phi\left(g\left(x_{n}\right), \bar{x}\right)-\phi\left(y, x_{n}\right)\right\} \\
=\liminf _{n \rightarrow \infty}\left\{\left\langle N\left(u_{n}, v_{n}\right), g\left(x_{n}\right)-y\right\rangle+\phi\left(g\left(x_{n}\right), x_{n}\right)-\phi\left(y, x_{n}\right)\right\} \\
\leq \liminf _{n \rightarrow \infty}\left\{\frac{\alpha}{2}\left\|g\left(x_{n}\right)-y\right\|^{2}+\epsilon_{n}^{\prime}\right\} \\
=\frac{\alpha}{2}\|g(\bar{x})-y\|^{2} .
\end{aligned}
$$

Since $F$ and $E$ are nonempty compact-valued mappings, in terms of Lemma 2.1, for each $u_{n} \in$ $F\left(x_{n}\right)$ and $v_{n} \in E\left(x_{n}\right)$ there exist $\bar{u}_{n} \in F(\bar{x})$ and $\bar{v}_{n} \in E(\bar{x})$ such that $\left\|u_{n}-\bar{u}_{n}\right\| \leq \mathscr{H}\left(F\left(x_{n}\right), F(\bar{x})\right)$ 
and $\left\|v_{n}-\bar{v}_{n}\right\| \leq \mathscr{H}\left(E\left(x_{n}\right), E(\bar{x})\right)$. Since $F$ and $E$ both are $\mathscr{H}$-continuous, one deduces that $\left\|u_{n}-\bar{u}_{n}\right\| \leq \mathscr{H}\left(F\left(x_{n}\right), F(\bar{x})\right) \rightarrow 0$ and $\left\|v_{n}-\bar{v}_{n}\right\| \leq \mathscr{H}\left(E\left(x_{n}\right), E(\bar{x})\right) \rightarrow 0$ as $n \rightarrow \infty$. Since $F(\bar{x})$ and $E(\bar{x})$ both are compact, without loss of generality we may assume that $\bar{u}_{n} \rightarrow \bar{u} \in F(\bar{x})$ and $\bar{v}_{n} \rightarrow \bar{v} \in E(\bar{x})$ as $n \rightarrow \infty$. Thus, we conclude that

$$
\left\|u_{n}-\bar{u}\right\| \leq\left\|u_{n}-\bar{u}_{n}\right\|+\left\|\bar{u}_{n}-\bar{u}\right\| \leq \mathscr{H}\left(F\left(x_{n}\right), F(\bar{x})\right)+\left\|\bar{u}_{n}-\bar{u}\right\| \rightarrow 0,
$$

and

$$
\left\|v_{n}-\bar{v}\right\| \leq\left\|v_{n}-\bar{v}_{n}\right\|+\left\|\bar{v}_{n}-\bar{v}\right\| \leq \mathscr{H}\left(E\left(x_{n}\right), E(\bar{x})\right)+\left\|\bar{v}_{n}-\bar{v}\right\| \rightarrow 0 .
$$

This implies that $u_{n} \rightarrow \bar{u}$ and $v_{n} \rightarrow \bar{v}$ as $n \rightarrow \infty$. Note that $N$ is mixed Lipschitz continuous with respect to the first and second arguments. Hence there exists a pair of constants $\zeta, \xi>0$ such that

$$
\left\|N\left(u_{n}, v_{n}\right)-N(\bar{u}, \bar{v})\right\| \leq \zeta\left\|u_{n}-\bar{u}\right\|+\xi\left\|v_{n}-\bar{v}\right\| \rightarrow 0 \quad \text { as } n \rightarrow \infty
$$

which together with (3.4), immediately yields

$$
\langle N(\bar{u}, \bar{v}), g(\bar{x})-y\rangle+\phi(g(\bar{x}), \bar{x})-\phi(y, \bar{x}) \leq \frac{\alpha}{2}\|g(\bar{x})-y\|^{2}, \quad \forall y \in K .
$$

For any $y \in K$, put $y_{t}=g(\bar{x})+t(y-g(\bar{x}))$ for all $t \in[0,1]$. Since $K$ is a nonempty, closed and convex subset, this implies that $y_{t} \in K$. Then

$$
\left\langle N(\bar{u}, \bar{v}), g(\bar{x})-y_{t}\right\rangle+\phi(g(\bar{x}), \bar{x})-\phi\left(y_{t}, \bar{x}\right) \leq \frac{\alpha}{2}\left\|g(\bar{x})-y_{t}\right\|^{2} .
$$

Since $\phi$ is convex in the first argument, we have

$$
\langle N(\bar{u}, \bar{v}), g(\bar{x})-y\rangle+\phi(g(\bar{x}), \bar{x})-\phi(y, \bar{x}) \leq \frac{\alpha t}{2}\|g(\bar{x})-y\|^{2}, \quad \forall y \in K .
$$

Letting $t \rightarrow 0^{+}$, from (3.5) we get

$$
\langle N(\bar{u}, \bar{v}), g(\bar{x})-y\rangle+\phi(g(\bar{x}), \bar{x})-\phi(y, \bar{x}) \leq 0, \quad \forall y \in K .
$$

Therefore, $\bar{x}$ solves CGMVI $(N(F, E), g, \phi, K)$.

To complete the proof, we need only to prove that $\operatorname{CGMVI}(N(F, E), g, \phi, K)$ has a unique solution. Assume by contradiction that $\operatorname{CGMVI}(N(F, E), g, \phi, K)$ has two distinct solutions $x_{1}$ and $x_{2}$ in $K$. Then it is easy to see that $x_{1}, x_{2} \in \Omega_{\alpha}(\epsilon)$ for all $\epsilon>0$ and

$$
0<\left\|x_{1}-x_{2}\right\| \leq \operatorname{diam}\left(\Omega_{\alpha}(\epsilon)\right) \rightarrow 0,
$$

a contradiction to (3.1). The proof is complete. 
Theorem 3.2. Let $K$ be a nonempty, closed and convex subset of $X$. Let $F, E: X \rightarrow 2^{X^{*}}$ be nonempty compact-valued mappings which both are upper semicontinuous. Let $g: X \rightarrow X$ be a continuous mapping and $N: X^{*} \times X^{*} \rightarrow X^{*}$ be mixed Lipschitz continuous with respect to the first and second arguments. Assume that $\phi: X \times X \rightarrow \mathbf{R} \cup\{+\infty\}$ satisfies the conditions:

(C1) $\phi$ is proper, convex and lower semicontinuous in the first argument;

(C2) $\phi$ is upper semicontinuous in the second argument;

(C3) $\liminf _{n \rightarrow \infty} \inf _{y \in \operatorname{dom} \phi\left(\cdot, x_{n}\right)}\left(\phi\left(y, x_{n}\right)-\phi(y, \bar{x})\right) \geq 0, \forall\left\{x_{n}\right\} \subset K: x_{n} \rightarrow \bar{x}(n \rightarrow \infty)$.

Then CGMVI $(N(F, E), g, \phi, K)$ is strongly LP $\alpha$-well-posed in the generalized sense if and only if

$$
\Omega_{\alpha}(\epsilon) \neq \varnothing, \quad \forall \epsilon>0 \text { and } \mu\left(\Omega_{\alpha}(\epsilon)\right) \rightarrow 0 \text { as } \epsilon \rightarrow 0 .
$$

Proof. Suppose that CGMVI $(N(F, E), g, \phi, K)$ is strongly LP $\alpha$-well-posed in the generalized sense. Let $S$ be the solution set of $\operatorname{CGMVI}(N(F, E), g, \phi, K)$. Then $S$ is nonempty and compact. Indeed, let $\left\{x_{n}\right\}$ be any sequence in $S$. Then $\left\{x_{n}\right\}$ is a LP $\alpha$-approximating sequence for CGMVI $(N(F, E), g, \phi, K)$. Since CGMVI $(N(F, E), g, \phi, K)$ is strongly LP $\alpha$-well-posed in the generalized sense, $\left\{x_{n}\right\}$ has a subsequence which converges strongly to some point of $S$. Thus $S$ is compact. It is obvious that $\varnothing \neq S \subset \Omega_{\alpha}(\epsilon)$ for all $\epsilon>0$. Now we show that

$$
\mu\left(\Omega_{\alpha}(\epsilon)\right) \rightarrow 0 \quad \text { as } \epsilon \rightarrow 0 .
$$

Observe that for every $\epsilon>0$,

$$
\mathscr{H}\left(\Omega_{\alpha}(\epsilon), S\right)=\max \left\{e\left(\Omega_{\alpha}(\epsilon), S\right), e\left(S, \Omega_{\alpha}(\epsilon)\right)\right\}=e\left(\Omega_{\alpha}(\epsilon), S\right) .
$$

Taking into account the compactness of $S$, we get

$$
\mu\left(\Omega_{\alpha}(\epsilon)\right) \leq 2 \mathscr{H}\left(\Omega_{\alpha}(\epsilon), S\right)+\mu(S)=2 e\left(\Omega_{\alpha}(\epsilon), S\right) .
$$

To prove (3.6), it is sufficient to show that

$$
e\left(\Omega_{\alpha}(\epsilon), S\right) \rightarrow 0 \quad \text { as } \epsilon \rightarrow 0 .
$$

Indeed, if $e\left(\Omega_{\alpha}(\epsilon), S\right) \nrightarrow 0$ as $\epsilon \rightarrow 0$, then there exist $l>0$ and $\left\{\epsilon_{n}\right\} \subset \mathbf{R}^{+}$with $\epsilon_{n} \rightarrow 0$, and $x_{n} \in$ $\Omega_{\alpha}\left(\epsilon_{n}\right)$ such that

$$
x_{n} \notin S+B(0, l), \quad \forall n \geq 1,
$$

where $B(0, l)$ is the closed ball centered at 0 with radius $l$. By the definition of $\Omega_{\alpha}\left(\epsilon_{n}\right)$, we know $d\left(g\left(x_{n}\right), K\right) \leq \epsilon_{n}<\epsilon_{n}+\frac{1}{n}$, and there exists $u_{n} \in F\left(x_{n}\right)$ and $v_{n} \in E\left(x_{n}\right)$ such that

$$
\left\langle N\left(u_{n}, v_{n}\right), g\left(x_{n}\right)-y\right\rangle+\phi\left(g\left(x_{n}\right), x_{n}\right)-\phi\left(y, x_{n}\right) \leq \frac{\alpha}{2}\left\|g\left(x_{n}\right)-y\right\|^{2}+\epsilon_{n}, \quad \forall y \in K .
$$


Thus, there exists $k_{n} \in K$ such that $\left\|k_{n}-g\left(x_{n}\right)\right\|<\epsilon_{n}+\frac{1}{n}$. Let $w_{n}=k_{n}-g\left(x_{n}\right)$, then we have $w_{n}+g\left(x_{n}\right) \in K$ with $w_{n} \rightarrow 0$. So $\left\{x_{n}\right\}$ is a LP $\alpha$-approximating sequence for $\operatorname{CGMVI}(N(F, E), g$, $\phi, K)$. Since CGMVI $(N(F, E), g, \phi, K)$ is strongly LP $\alpha$-well-posed in the generalized sense, there exists a subsequence $\left\{x_{n_{i}}\right\}$ of $\left\{x_{n}\right\}$ which converges strongly to some point of $S$. This contradicts (3.7) and so

$$
e\left(\Omega_{\alpha}(\epsilon), S\right) \rightarrow 0 \quad \text { as } \epsilon \rightarrow 0 .
$$

Conversely, assume that (3.6) holds. We first show that $\Omega_{\alpha}(\epsilon)$ is closed for all $\epsilon>0$. Let $\left\{x_{n}\right\} \subset \Omega_{\alpha}(\epsilon)$ with $x_{n} \rightarrow \bar{x}$. Then there exists $u_{n} \in F\left(x_{n}\right)$ and $v_{n} \in E\left(x_{n}\right)$ such that $d\left(g\left(x_{n}\right), K\right) \leq \epsilon$ and

$$
\left\langle N\left(u_{n}, v_{n}\right), g\left(x_{n}\right)-y\right\rangle+\phi\left(g\left(x_{n}\right), x_{n}\right)-\phi\left(y, x_{n}\right) \leq \frac{\alpha}{2}\left\|g\left(x_{n}\right)-y\right\|^{2}+\epsilon, \quad \forall y \in K, n \geq 1 .
$$

Since $F$ and $E$ are nonempty compact-valued mappings which both are upper semicontinuous, there exist subsequences $\left\{u_{n_{i}}\right\} \subset\left\{u_{n}\right\}$ and $\left\{v_{n_{i}}\right\} \subset\left\{v_{n}\right\}$ such that $u_{n_{i}} \rightarrow \bar{u}$ and $v_{n_{i}} \rightarrow \bar{v}$ for some $\bar{u} \in F(\bar{x})$ and $\bar{v} \in E(\bar{x})$. Note that $g$ is continuous and $N$ is mixed Lipschitz continuous with respect to the first and second arguments. So it follows that $g\left(x_{n_{i}}\right) \rightarrow g(\bar{x})$ and $N\left(u_{n_{i}}, v_{n_{i}}\right) \rightarrow N(\bar{u}, \bar{v})$ as $i \rightarrow \infty$. Therefore, utilizing the similar argument process to that in the proof of Theorem 3.1, we obtain from (3.8) and conditions (C1)-(C3) that

$$
\langle N(\bar{u}, \bar{v}), g(\bar{x})-y\rangle+\phi(g(\bar{x}), \bar{x})-\phi(y, \bar{x}) \leq \frac{\alpha}{2}\|g(\bar{x})-y\|^{2}+\epsilon, \quad \forall y \in K .
$$

It is easy to see that $d(\bar{x}, K) \leq \epsilon$. This shows that $\bar{x} \in \Omega_{\alpha}(\epsilon)$ and so $\Omega_{\alpha}(\epsilon)$ is nonempty closed for all $\epsilon>0$. Observe that

$$
S=\bigcap_{\epsilon>0} \Omega_{\alpha}(\epsilon)
$$

Since $\mu\left(\Omega_{\alpha}(\epsilon)\right) \rightarrow 0$, the theorem in page 412 of [15] can be applied and one concludes that $S$ is nonempty and compact with

$$
e\left(\Omega_{\alpha}(\epsilon), S\right)=\mathscr{H}\left(\Omega_{\alpha}(\epsilon), S\right) \rightarrow 0 .
$$

Let $\left\{\widehat{x}_{n}\right\} \subset K$ be a LP $\alpha$-approximating sequence for $\operatorname{CGMVI}(N(F, E), g, \phi, K)$. Then there exists $w_{n} \in X$ with $w_{n} \rightarrow 0$ such that $g\left(\widehat{x}_{n}\right)+w_{n} \in K$, and there exist $\widehat{u}_{n} \in F\left(\widehat{x}_{n}\right), \widehat{v}_{n} \in E\left(\widehat{x}_{n}\right)$ and $0<\epsilon_{n}^{\prime} \rightarrow 0$ such that

$$
\left\langle N\left(\widehat{u}_{n}, \widehat{v}_{n}\right), g\left(\widehat{x}_{n}\right)-y\right\rangle+\phi\left(g\left(\widehat{x}_{n}\right), \widehat{x}_{n}\right)-\phi\left(y, \widehat{x}_{n}\right) \leq \frac{\alpha}{2}\left\|g\left(\widehat{x}_{n}\right)-y\right\|^{2}+\epsilon_{n}^{\prime}, \quad \forall y \in K, n \geq 1 .
$$

Since $g\left(\widehat{x}_{n}\right)+w_{n} \in K$, then there exists $k_{n} \in K$ such that $g\left(\widehat{x}_{n}\right)+w_{n}=k_{n}$. It follows that

$$
d\left(g\left(\widehat{x}_{n}\right), K\right) \leq\left\|g\left(\widehat{x}_{n}\right)-k_{n}\right\|=\left\|w_{n}\right\| \rightarrow 0 .
$$


Set $\epsilon_{n}=\max \left\{\left\|w_{n}\right\|, \epsilon_{n}^{\prime}\right\}$, we get $\widehat{x}_{n} \in \Omega_{\alpha}\left(\epsilon_{n}\right)$. From (3.6) and the definition of $\Omega_{\alpha}\left(\epsilon_{n}\right)$, we have

$$
d\left(\widehat{x}_{n}, S\right) \leq e\left(\Omega_{\alpha}\left(\epsilon_{n}\right), S\right) \rightarrow 0 .
$$

Since $S$ is compact, there exists $p_{n} \in S$ such that

$$
\left\|p_{n}-\widehat{x}_{n}\right\|=d\left(\widehat{x}_{n}, S\right) \rightarrow 0
$$

Again from the compactness of $S$, there exists a subsequence $\left\{p_{n_{i}}\right\}$ of $\left\{p_{n}\right\}$ which converges strongly to $\bar{p} \in S$. Hence the corresponding subsequence $\left\{\widehat{x}_{n_{i}}\right\}$ of $\left\{\widehat{x}_{n}\right\}$ converges strongly to $\bar{p} \in S$. Therefore, CGMVI $(N(F, E), g, \phi, K)$ is strongly LP $\alpha$-well-posed in the generalized sense. The proof is complete.

Remark 3.2. Our Theorems 3.1 and 3.2 improve, extend and develop Theorems 3.1 and 3.2 in [19] to a great extent because our CGMVI $(N(F, E), g, \phi, K)$ is more general than the GMVI(F, $\phi$, $K)$ in [19].

\section{Links with Levitin-Polyak Well-Posedness of Inclusion Problems}

In this section, we shall show that the Levitin-Polyak well-posedness of a completely generalized mixed variational inequality is closely related to the Levitin-Polyak well-posedness of a inclusion problem. Let $g: X \rightarrow X$ be a single-valued mapping and $A: X \times X \rightarrow 2^{X^{*}}$ be a setvalued mapping. The inclusion problem associated with $(A, g, K)$ is defined by

$$
\operatorname{IP}(A, g, K) \text { : find } x \in K \text { such that } 0 \in A(x, g(x)) \text {. }
$$

Definition 4.1. A sequence $\left\{x_{n}\right\} \subset K$ is called a $\operatorname{LP}$ approximating sequence for $\operatorname{IP}(A, g, K)$ if there exists $w_{n} \in X$ with $w_{n} \rightarrow 0$ such that $g\left(x_{n}\right)+w_{n} \in K$ and $d\left(0, A\left(x_{n}, g\left(x_{n}\right)\right)\right) \rightarrow 0$ as $n \rightarrow \infty$, or equivalently, there exists $y_{n} \in A\left(x_{n}, g\left(x_{n}\right)\right)$ such that $\left\|y_{n}\right\| \rightarrow 0$ as $n \rightarrow \infty$.

Definition 4.2. We say that $\operatorname{IP}(A, g, K)$ is strongly (resp. weakly) LP well-posed if it has a unique solution and every LP approximating sequence converges strongly (resp. weakly) to the unique solution of $\operatorname{IP}(A, g, K)$. $\operatorname{IP}(A, g, K)$ is said to be strongly (resp. weakly) LP well-posed in the generalized sense if the solution set $S$ of $\operatorname{IP}(A, g, K)$ is nonempty and every LP approximating sequence has a subsequence which converges strongly (resp. weakly) to a point of $S$.

Remark 4.1. When $g=I$, Definitions 4.1 and 4.2 coincide with the Definitions 4.1 and 4.2 in [19], respectively. When $X$ is a real Hilbert space, $g=I, K=X$ and $w_{n} \equiv 0$, Definitions 4.1 and 4.2 coincide with the Definitions 4.1 and 4.2 in [11], respectively. 
Theorem 4.1. Let $K$ be a nonempty, compact and convex subset of $X$. Let $F, E: X \rightarrow 2^{X^{*}}$ be nonempty compact-valued mappings which both are $\mathscr{H}$-continuous. Let $g: X \rightarrow X$ be a continuous mapping and $N: X^{*} \times X^{*} \rightarrow X^{*}$ be mixed Lipschitz continuous with respect to the first and second arguments. Assume that $\phi: X \times X \rightarrow \mathbf{R} \cup\{+\infty\}$ satisfies the conditions:

(C1) $\phi$ is proper, convex and lower semicontinuous in the first argument;

(C2) $\phi$ is upper semicontinuous in the second argument;

(C3) $\liminf _{n \rightarrow \infty} \inf _{y \in \operatorname{dom} \phi\left(\cdot, x_{n}\right)}\left(\phi\left(y, x_{n}\right)-\phi(y, \bar{x})\right) \geq 0, \forall\left\{x_{n}\right\} \subset K: x_{n} \rightarrow \bar{x}(n \rightarrow \infty)$.

If CGMVI $(N(F, E), g, \phi, K)$ is strongly LP well-posed, then $\operatorname{IP}\left(N(F, E)+\partial\left(\phi+\delta_{K}\right) \circ g, K\right)$ is strongly LP well-posed.

Proof. Suppose that CGMVI $(N(F, E), g, \phi, K)$ is strongly LP well-posed and $x^{*}$ is the unique solution of $\operatorname{CGMVI}(N(F, E), g, \phi, K)$. By Proposition 2.1, we obtain that $x^{*}$ is also the unique solution of $\operatorname{IP}\left(N(F, E)+\partial\left(\phi+\delta_{K}\right) \circ g, K\right)$. Let $\left\{x_{n}\right\}$ be a LP approximating sequence for $\operatorname{IP}(N(F, E)+$ $\left.\partial\left(\phi+\delta_{K}\right) \circ g, K\right)$. Then, there exists $w_{n} \in X$ with $w_{n} \rightarrow 0$ such that $g\left(x_{n}\right)+w_{n} \in K$, and there exists $y_{n} \in N\left(F\left(x_{n}\right), E\left(x_{n}\right)\right)+\partial\left(\phi\left(\cdot, x_{n}\right)+\delta_{K}\right)\left(g\left(x_{n}\right)\right)$ such that $\left\|y_{n}\right\| \rightarrow 0$ as $n \rightarrow \infty$. It is easy to see that there exist $u_{n} \in F\left(x_{n}\right)$ and $v_{n} \in E\left(x_{n}\right)$ such that

$$
\phi\left(y, x_{n}\right)-\phi\left(g\left(x_{n}\right), x_{n}\right) \geq\left\langle y_{n}-N\left(u_{n}, v_{n}\right), y-g\left(x_{n}\right)\right\rangle, \quad \forall y \in K .
$$

Let $\left\{x_{n_{i}}\right\}$ be any subsequence of $\left\{x_{n}\right\}$ such that $x_{n_{i}} \rightarrow \bar{x}$ as $i \rightarrow \infty$. Clearly $\bar{x} \in K$. Since $\left\{g\left(x_{n}\right)\right\} \subset K$ and $g$ is continuous, we obtain from $g\left(x_{n}\right)+w_{n} \in K$ and $w_{n} \rightarrow 0$ that $g(\bar{x}) \in K$. So, it follows from (4.1), $\left\|y_{n}\right\| \rightarrow 0$ and conditions (C1)-(C3) that

$$
\liminf _{i \rightarrow \infty}\left(\phi\left(g\left(x_{n_{i}}\right), x_{n_{i}}\right)-\phi\left(g\left(x_{n_{i}}\right), \bar{x}\right)\right) \geq \liminf _{i \rightarrow \infty} \inf _{y \in \operatorname{dom} \phi\left(\cdot, x_{n_{i}}\right)}\left(\phi\left(y, x_{n_{i}}\right)-\phi(y, \bar{x})\right) \geq 0,
$$

and

$$
\begin{aligned}
& \liminf _{i \rightarrow \infty}\left\langle N\left(u_{n_{i}}, v_{n_{i}}\right), g\left(x_{n_{i}}\right)-y\right\rangle+\phi(g(\bar{x}), \bar{x})-\phi(y, \bar{x}) \\
& \leq \liminf _{i \rightarrow \infty}\left\langle N\left(u_{n_{i}}, v_{n_{i}}\right)-y_{n_{i}}, g\left(x_{n_{i}}\right)-y\right\rangle+\liminf _{i \rightarrow \infty} \phi\left(g\left(x_{n_{i}}\right), \bar{x}\right) \\
& \quad+\liminf _{i \rightarrow \infty}\left(\phi\left(g\left(x_{n_{i}}\right), x_{n_{i}}\right)-\phi\left(g\left(x_{n_{i}}\right), \bar{x}\right)\right)+\liminf _{i \rightarrow \infty}\left(-\phi\left(y, x_{n_{i}}\right)\right) \\
& \leq \liminf _{i \rightarrow \infty}\left\{\left\langle N\left(u_{n_{i}}, v_{n_{i}}\right)-y_{n_{i}}, g\left(x_{n_{i}}\right)-y\right\rangle+\phi\left(g\left(x_{n_{i}}\right), \bar{x}\right)\right. \\
& \left.\quad+\phi\left(g\left(x_{n_{i}}\right), x_{n_{i}}\right)-\phi\left(g\left(x_{n_{i}}\right), \bar{x}\right)-\phi\left(y, x_{n_{i}}\right)\right\} \\
& =\liminf _{i \rightarrow \infty}\left\{\left\langle N\left(u_{n_{i}}, v_{n_{i}}\right)-y_{n_{i}}, g\left(x_{n_{i}}\right)-y\right\rangle+\phi\left(g\left(x_{n_{i}}\right), x_{n_{i}}\right)-\phi\left(y, x_{n_{i}}\right)\right\} \\
& \leq 0 .
\end{aligned}
$$

Since $F$ and $E$ are nonempty compact-valued mappings, in terms of Lemma 2.1, for each $u_{n} \in$ $F\left(x_{n}\right)$ and $v_{n} \in E\left(x_{n}\right)$ there exist $\bar{u}_{n} \in F(\bar{x})$ and $\bar{v}_{n} \in E(\bar{x})$ such that $\left\|u_{n}-\bar{u}_{n}\right\| \leq \mathscr{H}\left(F\left(x_{n}\right), F(\bar{x})\right)$ and $\left\|v_{n}-\bar{v}_{n}\right\| \leq \mathscr{H}\left(E\left(x_{n}\right), E(\bar{x})\right)$. Since $F$ and $E$ both are $\mathscr{H}$-continuous, one deduces that $\left\|u_{n_{i}}-\bar{u}_{n_{i}}\right\| \leq \mathscr{H}\left(F\left(x_{n_{i}}\right), F(\bar{x})\right) \rightarrow 0$ and $\left\|v_{n_{i}}-\bar{v}_{n_{i}}\right\| \leq \mathscr{H}\left(E\left(x_{n_{i}}\right), E(\bar{x})\right) \rightarrow 0$ as $i \rightarrow \infty$. Since $F(\bar{x})$ 
and $E(\bar{x})$ both are compact, without loss of generality we may assume that $\bar{u}_{n_{i}} \rightarrow \bar{u} \in F(\bar{x})$ and $\bar{v}_{n_{i}} \rightarrow \bar{v} \in E(\bar{x})$ as $i \rightarrow \infty$. Thus, we conclude that

$$
\left\|u_{n_{i}}-\bar{u}\right\| \leq\left\|u_{n_{i}}-\bar{u}_{n_{i}}\right\|+\left\|\bar{u}_{n_{i}}-\bar{u}\right\| \rightarrow 0 \quad \text { as } i \rightarrow \infty \text {, }
$$

and

$$
\left\|v_{n_{i}}-\bar{v}\right\| \leq\left\|v_{n_{i}}-\bar{v}_{n_{i}}\right\|+\left\|\bar{v}_{n_{i}}-\bar{v}\right\| \rightarrow 0 \quad \text { as } i \rightarrow \infty .
$$

That is, $u_{n_{i}} \rightarrow \bar{u}$ and $v_{n_{i}} \rightarrow \bar{v}$ as $i \rightarrow \infty$. Note that $N$ is mixed Lipschitz continuous with respect to the first and second arguments. Hence there exists a pair of constants $\zeta, \xi>0$ such that

$$
\left\|N\left(u_{n_{i}}, v_{n_{i}}\right)-N(\bar{u}, \bar{v})\right\| \leq \zeta\left\|u_{n_{i}}-\bar{u}\right\|+\xi\left\|v_{n_{i}}-\bar{v}\right\| \rightarrow 0 \quad \text { as } i \rightarrow \infty
$$

So, it immediately follows from (4.4) that

$$
\langle N(\bar{u}, \bar{v}), g(\bar{x})-y\rangle+\phi(g(\bar{x}), \bar{x})-\phi(y, \bar{x}) \leq 0, \quad \forall y \in K .
$$

Thus, $\bar{x}$ solves CGMVI $(N(F, E), g, \phi, K)$. Since CGMVI $(N(F, E), g, \phi, K)$ has a unique solution $x^{*}$, we get $\bar{x}=x^{*}$. This shows that $x_{n} \rightarrow x^{*}$ as $n \rightarrow \infty$. Therefore, $\operatorname{IP}\left(N(F, E)+\partial\left(\phi+\delta_{K}\right) \circ g, K\right)$ is strongly LP well-posed. The proof is complete.

Theorem 4.2. Let $K$ be a nonempty, closed and convex subset of $X$. Let $F, E: X \rightarrow 2^{X^{*}}$ be nonempty compact-valued mappings which both are $\mathscr{H}$-uniformly continuous. Let $g: X \rightarrow X$ be a homeomorphic mapping and $N: X^{*} \times X^{*} \rightarrow X^{*}$ be mixed Lipschitz continuous with respect to the first and second arguments. Assume that $\phi: X \times X \rightarrow \mathbf{R} \cup\{+\infty\}$ satisfies the conditions:

(C1) $\phi$ is proper, convex and subdifferentiable in the first argument, and for each $y \in X$ the subdifferential of $\phi(\cdot, y)$ at $x \in X$ is denoted by $\partial_{1} \phi(x, y)$;

(C2) for each $y \in X, \partial_{1} \phi(\cdot, y): X \rightarrow 2^{X^{*}}$ is a nonempty compact-valued mapping, which is $\mathscr{H}$ Lipschitz continuous with respect to $g$, that is, for some $\lambda>0$, one has

$$
\mathscr{H}\left(\partial_{1} \phi(g(x), y), \partial_{1} \phi(g(x), z)\right) \leq \lambda\|g(y)-g(z)\|, \quad \forall x, y, z \in X
$$

If $\operatorname{IP}\left(N(F, E)+\partial\left(\phi+\delta_{K}\right) \circ g, K\right)$ is strongly LP well-posed, then $\operatorname{CGMVI}(N(F, E), g, \phi, K)$ is strongly LP well-posed.

Proof. Let $\left\{x_{n}\right\} \subset K$ be a LP approximating sequence for CGMVI $(N(F, E), g, \phi, K)$. Then there exist $w_{n} \in X$ with $w_{n} \rightarrow 0$ and $0<\epsilon_{n} \rightarrow 0$ such that $g\left(x_{n}\right)+w_{n} \in K$, and there exist $u_{n} \in F\left(x_{n}\right)$ and $v_{n} \in E\left(x_{n}\right)$ satisfying

$$
\phi\left(g\left(x_{n}\right), x_{n}\right) \geq \phi\left(y, x_{n}\right)+\left\langle N\left(u_{n}, v_{n}\right), y-g\left(x_{n}\right)\right\rangle+\epsilon_{n}, \quad \forall y \in K, n \geq 1 .
$$


Since $g\left(x_{n}\right)+w_{n} \in K$, there exists $k_{n} \in K$ such that $g\left(x_{n}\right)+w_{n}=k_{n}$.

Define $\tilde{\phi}_{n}: X \rightarrow \mathbf{R} \cup\{+\infty\}$ as follows:

$$
\tilde{\phi}_{n}(y)=\phi\left(y, x_{n}\right)+\left\langle N\left(u_{n}, v_{n}\right), y-g\left(x_{n}\right)\right\rangle, \quad \forall y \in K, n \geq 1 .
$$

Since $\phi$ is proper, convex and subdifferentiable in the first argument, then we have that $\tilde{\phi}_{n}$ is proper, convex and subdifferentiable for all $n \geq 1$. It follows from Proposition 2.2.6 of [16] that $\tilde{\phi}_{n}$ is Lipschitz continuous. Since $\left\|w_{n}\right\|=\left\|k_{n}-g\left(x_{n}\right)\right\| \rightarrow 0$, then there exists $0<\delta_{n} \rightarrow 0$ such that

$$
\tilde{\phi}_{n}\left(k_{n}\right)-\tilde{\phi}_{n}\left(g\left(x_{n}\right)\right) \leq \delta_{n}
$$

By (4.5) and (4.6), we have

$$
\tilde{\phi}_{n}\left(k_{n}\right) \leq \tilde{\phi}_{n}(y)+\delta_{n}+\epsilon_{n}, \quad \forall y \in K .
$$

By Ekeland's theorem [17], there exists $\widetilde{x}_{n} \in K$ such that

$$
\left\|g\left(\widetilde{x}_{n}\right)-k_{n}\right\| \leq \sqrt{\delta_{n}+\epsilon_{n}}
$$

and

$$
\tilde{\phi}_{n}\left(g\left(\widetilde{x}_{n}\right)\right) \leq \tilde{\phi}_{n}(y)+\sqrt{\delta_{n}+\epsilon_{n}}\left\|y-g\left(\widetilde{x}_{n}\right)\right\|, \quad \forall y \in K .
$$

Thus, $g\left(\widetilde{x}_{n}\right)$ minimizes the function $\tilde{\phi}_{n}\left((\cdot)+\sqrt{\delta_{n}+\epsilon_{n}}\left\|\cdot-g\left(\widetilde{x}_{n}\right)\right\|\right.$. It follows that $0^{*} \in \partial\left(\tilde{\phi}_{n}((\cdot)+\right.$ $\left.\sqrt{\delta_{n}+\epsilon_{n}}\left\|\cdot-g\left(\widetilde{x}_{n}\right)\right\|\right)\left(g\left(\widetilde{x}_{n}\right)\right)$. That is,

$$
0^{*} \in \partial \tilde{\phi}_{n}\left(g\left(\widetilde{x}_{n}\right)\right)+\sqrt{\delta_{n}+\epsilon_{n}} B_{X^{*}}
$$

So there exists

$$
x_{n}^{*} \in \partial \tilde{\phi}_{n}\left(g\left(\widetilde{x}_{n}\right)\right)=\partial \phi_{1}\left(g\left(\widetilde{x}_{n}\right), x_{n}\right)+N\left(u_{n}, v_{n}\right)
$$

such that

$$
\left\|x_{n}^{*}\right\| \leq \sqrt{\delta_{n}+\epsilon_{n}} .
$$

Since $\left\|g\left(x_{n}\right)-k_{n}\right\| \rightarrow 0$ and $\left\|g\left(\widetilde{x}_{n}\right)-k_{n}\right\| \rightarrow 0$, we know that $\left\|g\left(\widetilde{x}_{n}\right)-g\left(x_{n}\right)\right\| \leq\left\|g\left(\widetilde{x}_{n}\right)-k_{n}\right\|+$ $\left\|g\left(x_{n}\right)-k_{n}\right\| \rightarrow 0$. Since $F$ and $E$ are nonempty compact-valued mappings which both are $\not{H}$ uniformly continuous, by Lemma 2.1 we deduce that for each $u_{n} \in F\left(x_{n}\right)$ and $v_{n} \in E\left(x_{n}\right)$ there exist $\widetilde{u}_{n} \in F\left(\widetilde{x}_{n}\right)$ and $\widetilde{v}_{n} \in E\left(\widetilde{x}_{n}\right)$ such that $\left\|u_{n}-\widetilde{u}_{n}\right\| \leq \mathscr{H}\left(F\left(x_{n}\right), F\left(\widetilde{x}_{n}\right)\right) \rightarrow 0$ and $\left\|v_{n}-\widetilde{v}_{n}\right\| \leq$ $\mathscr{H}\left(E\left(x_{n}\right), E\left(\widetilde{x}_{n}\right)\right) \rightarrow 0$.

On the other hand, putting $z_{n}=x_{n}^{*}-N\left(u_{n}, v_{n}\right)$, from (4.7) we get $z_{n} \in \partial \phi_{1}\left(g\left(\widetilde{x}_{n}\right), x_{n}\right)$. Since for each $y \in X, \partial_{1} \phi(\cdot, y): X \rightarrow 2^{X^{*}}$ is a nonempty compact-valued mapping, which is $\mathscr{H}$-Lipschitz continuous with respect to $g$, we obtain that for each $z_{n} \in \partial \phi_{1}\left(g\left(\widetilde{x}_{n}\right), x_{n}\right)$, there exists $\widetilde{z}_{n} \in \partial \phi_{1}\left(g\left(\widetilde{x}_{n}\right), \widetilde{x}_{n}\right)$ such that for some $\lambda>0$,

$$
\left\|z_{n}-\widetilde{z}_{n}\right\| \leq \mathscr{H}\left(\partial \phi_{1}\left(g\left(\widetilde{x}_{n}\right), x_{n}\right), \partial \phi_{1}\left(g\left(\widetilde{x}_{n}\right), \widetilde{x}_{n}\right)\right) \leq \lambda\left\|g\left(x_{n}\right)-g\left(\widetilde{x}_{n}\right)\right\| \rightarrow 0 .
$$


Putting $e_{n}=z_{n}-\widetilde{z}_{n}$, we deduce from (4.7) that

$$
\begin{aligned}
x_{n}^{*} & +N\left(\widetilde{u}_{n}, \widetilde{v}_{n}\right)-N\left(u_{n}, v_{n}\right)-e_{n}+\partial \delta_{K}\left(g\left(\widetilde{x}_{n}\right)\right) \\
& =N\left(\widetilde{u}_{n}, \widetilde{v}_{n}\right)+z_{n}-e_{n}+\partial \delta_{K}\left(g\left(\widetilde{x}_{n}\right)\right) \\
& =N\left(\widetilde{u}_{n}, \widetilde{v}_{n}\right)+\widetilde{z}_{n}+\partial \delta_{K}\left(g\left(\widetilde{x}_{n}\right)\right) \\
& \subset N\left(\widetilde{u}_{n}, \widetilde{v}_{n}\right)+\partial \phi_{1}\left(g\left(\widetilde{x}_{n}\right), \widetilde{x}_{n}\right)+\partial \delta_{K}\left(g\left(\widetilde{x}_{n}\right)\right) \\
& \subset N\left(F\left(\widetilde{x}_{n}\right), E\left(\widetilde{x}_{n}\right)+\partial\left(\phi\left(\cdot, \widetilde{x}_{n}\right)+\delta_{K}\right)\left(g\left(\widetilde{x}_{n}\right)\right) .\right.
\end{aligned}
$$

From $0^{*} \in \partial \delta_{K}\left(g\left(\widetilde{x}_{n}\right)\right)$, we have

$$
x_{n}^{*}+N\left(\widetilde{u}_{n}, \widetilde{v}_{n}\right)-N\left(u_{n}, v_{n}\right)-e_{n} \in N\left(F\left(\widetilde{x}_{n}\right), E\left(\widetilde{x}_{n}\right)+\partial\left(\phi\left(\cdot, \widetilde{x}_{n}\right)+\delta_{K}\right)\left(g\left(\widetilde{x}_{n}\right)\right) .\right.
$$

Since $N$ be mixed Lipschitz continuous with respect to the first and second arguments, there exists a pair of constants $\zeta, \xi>0$ such that

$$
\left\|N\left(u_{n}, v_{n}\right)-N\left(\widetilde{u}_{n}, \widetilde{v}_{n}\right)\right\| \leq \zeta\left\|u_{n}-\widetilde{u}_{n}\right\|+\xi\left\|v_{n}-\widetilde{v}_{n}\right\| \rightarrow 0
$$

Combining (4.7)-(4.9), we get

$$
\left\|x_{n}^{*}+N\left(\widetilde{u}_{n}, \widetilde{v}_{n}\right)-N\left(u_{n}, v_{n}\right)-e_{n}\right\| \leq\left\|x_{n}^{*}\right\|+\left\|N\left(\widetilde{u}_{n}, \widetilde{v}_{n}\right)-N\left(u_{n}, v_{n}\right)\right\|+\left\|e_{n}\right\| \rightarrow 0 .
$$

This shows that $\left\{\widetilde{x}_{n}\right\}$ is a LP approximating sequence for $\operatorname{IP}\left(N(F, E)+\partial\left(\phi+\delta_{K}\right) \circ g, K\right)$. Let $x^{*}$ be the unique solution of $\operatorname{IP}\left(N(F, E)+\partial\left(\phi+\delta_{K}\right) \circ g, K\right)$. By Proposition 2.1, $x^{*}$ is also the unique solution of CGMVI $(N(F, E), g, \phi, K)$. If $\operatorname{IP}\left(N(F, E)+\partial\left(\phi+\delta_{K}\right) \circ g, K\right)$ is strongly LP well-posed, then $\widetilde{x}_{n} \rightarrow x^{*}$. Noticing that $\left\|g\left(x_{n}\right)-g\left(x^{*}\right)\right\| \leq\left\|g\left(x_{n}\right)-g\left(\widetilde{x}_{n}\right)\right\|+\left\|g\left(\widetilde{x}_{n}\right)-g\left(x^{*}\right)\right\|$, we know that $g\left(x_{n}\right) \rightarrow g\left(x^{*}\right)$ as $n \rightarrow \infty$. Since $g: X \rightarrow X$ is a homeomorphic mapping, we immediately obtain that $x_{n} \rightarrow x^{*}$ as $n \rightarrow \infty$. Thus, CGMVI $(N(F, E), g, \phi, K)$ is strongly LP well-posed.

Theorem 4.3. Let $K$ be a nonempty, closed and convex subset of $X$. Let $F, E: X \rightarrow 2^{X^{*}}$ be nonempty compact-valued mappings. Let $g: X \rightarrow X$ be a continuous mapping and $N: X^{*} \times$ $X^{*} \rightarrow X^{*}$ be a continuous mapping. Assume that $\phi: X \times X \rightarrow \mathbf{R} \cup\{+\infty\}$ is proper, convex and lower semicontinuous in the first argument. If CGMVI $(N(F, E), g, \phi, K)$ is strongly (resp. weakly) LP 1-well-posed in the generalized sense, then $\operatorname{IP}\left(N(F, E)+\partial\left(\phi+\delta_{K}\right) \circ g, K\right)$ is strongly (resp. weakly) LP well-posed in the generalized sense.

Proof. Let $\left\{x_{n}\right\}$ be a LP approximating sequence for $\operatorname{IP}\left(N(F, E)+\partial\left(\phi+\delta_{K}\right) \circ g, K\right)$. Then there exists $w_{n} \in X$ with $w_{n} \rightarrow 0$ such that $g\left(x_{n}\right)+w_{n} \in K$, and there exists $y_{n} \in N\left(F\left(x_{n}\right), E\left(x_{n}\right)\right)+$ $\partial\left(\phi\left(\cdot, x_{n}\right)+\delta_{K}\right)\left(g\left(x_{n}\right)\right)$ such that $\left\|y_{n}\right\| \rightarrow 0$ as $n \rightarrow \infty$. It is easy to see that there exist $u_{n} \in F\left(x_{n}\right)$ and $v_{n} \in E\left(x_{n}\right)$ such that

$$
\phi\left(y, x_{n}\right)-\phi\left(g\left(x_{n}\right), x_{n}\right) \geq\left\langle y_{n}-N\left(u_{n}, v_{n}\right), y-g\left(x_{n}\right)\right\rangle, \quad \forall y \in K .
$$


Thus,

$$
\begin{aligned}
& \left\langle N\left(u_{n}, v_{n}\right), g\left(x_{n}\right)-y\right\rangle+\phi\left(g\left(x_{n}\right), x_{n}\right)-\phi\left(y, x_{n}\right) \\
& \leq\left\langle y_{n}, g\left(x_{n}\right)-y\right\rangle \leq \frac{1}{2}\left\|g\left(x_{n}\right)-y\right\|^{2}+\frac{1}{2}\left\|y_{n}\right\|^{2}, \quad \forall y \in K, n \geq 1 .
\end{aligned}
$$

This together with $\left\|y_{n}\right\| \rightarrow 0$, implies that $\left\{x_{n}\right\}$ be a LP 1-approximating sequence for $\operatorname{CGMVI}(N(F, E), g, \phi, K)$. Since CGMVI $(N(F, E), g, \phi, K)$ is strongly (resp. weakly) LP 1-wellposed in the generalized sense, $\left\{x_{n}\right\}$ has a subsequence which converges strongly (resp. weakly) to some solution $x^{*}$ of $\operatorname{CGMVI}(N(F, E), g, \phi, K)$. By Proposition 2.1, $x^{*}$ is also a solution of $\operatorname{IP}\left(N(F, E)+\partial\left(\phi+\delta_{K}\right) \circ g, K\right)$ and so $\operatorname{IP}\left(N(F, E)+\partial\left(\phi+\delta_{K}\right) \circ g, K\right)$ is strongly (resp. weakly) LP well-posed in the generalized sense. The proof is complete.

Theorem 4.4. Let $K$ be a nonempty, closed and convex subset of $X$. Let $F, E: X \rightarrow 2^{X^{*}}$ be nonempty compact-valued mappings which both are $\mathscr{H}$-uniformly continuous. Let $g: X \rightarrow X$ be a homeomorphic mapping and $N: X^{*} \times X^{*} \rightarrow X^{*}$ be mixed Lipschitz continuous with respect to the first and second arguments. Assume that $\phi: X \times X \rightarrow \mathbf{R} \cup\{+\infty\}$ satisfies the conditions:

(C1) $\phi$ is proper, convex and subdifferentiable in the first argument, and for each $y \in X$ the subdifferential of $\phi(\cdot, y)$ at $x \in X$ is denoted by $\partial_{1} \phi(x, y)$;

(C2) for each $y \in X, \partial_{1} \phi(\cdot, y): X \rightarrow 2^{X^{*}}$ is a nonempty compact-valued mapping, which is $\mathscr{H}$ Lipschitz continuous with respect to $g$, that is, for some $\lambda>0$, one has

$$
\mathscr{H}\left(\partial_{1} \phi(g(x), y), \partial_{1} \phi(g(x), z)\right) \leq \lambda\|g(y)-g(z)\|, \quad \forall x, y, z \in X
$$

If $\operatorname{IP}\left(N(F, E)+\partial\left(\phi+\delta_{K}\right) \circ g, K\right)$ is strongly LP well-posed in the generalized sense, then $\operatorname{CGMVI}(N(F, E), g, \phi, K)$ is strongly LP well-posed in the generalized sense.

Proof. The conclusion follows from the similar arguments to those in the proof of Theorem 4.2 .

Remark 4.2. Our Theorems 4.1-4.4 improve, extend and develop Theorems 4.1-4.4 in [19] to a great extent because our CGMVI $(N(F, E), g, \phi, K)$ and $\operatorname{IP}\left(N(F, E)+\partial\left(\phi+\delta_{K}\right) \circ g, K\right)$ are more general than the $\operatorname{GMVI}(F, \phi, K)$ and $\operatorname{IP}\left(F+\partial\left(\phi+\delta_{K}\right), K\right)$ in [19], respectively.

\section{Links with Levitin-Polyak Well-Posedness of fixed point problems}

In this section, we shall investigate the relations between the Levitin-Polyak well-posedness of completely generalized mixed variational inequalities and the Levitin-Polyak well-posedness of the corresponding fixed point problems. Let $g: X \rightarrow X$ be a single-valued mapping and 
$T: X \times X \rightarrow 2^{X^{*}}$ be a set-valued mapping. The fixed point problem associated with $(T, g, K)$ is defined by

$$
\operatorname{FP}(T, g, K) \text { : find } x \in K \text { such that } x \in T(x, g(x)) \text {. }
$$

Let $U=\{x \in X:\|x\|=1\}$ be the unit sphere. A Banach space $X$ is said to be (i) strictly convex if for any $x, y \in U, x \neq y \Rightarrow\left\|\frac{x+y}{2}\right\|<1$; (ii) smooth if the $\operatorname{limit}_{t \rightarrow 0} \frac{\|x+t y\|-\|x\|}{t}$ exists for all $x, y \in U$. The modulus of convexity of $X$ is defined by

$$
\delta_{X}(\epsilon)=\inf \left\{1-\left\|\frac{x+y}{2}\right\|: x, y \in U,\|x+y\| \geq \epsilon\right\},
$$

and the modulus of smoothness of $X$ is defined by

$$
\rho_{X}(\tau)=\sup \left\{\frac{1}{2}(\|x+y\|+\|x-y\|)-1: x \in U,\|y\| \leq \tau\right\} .
$$

In this section, we suppose that $q>1$ and $s>1$ are fixed numbers.

Definition 5.1. A Banach space $X$ is said to be

(i) $q$-uniformly convex if there exists a constant $c>0$ such that $\delta_{X}(\epsilon) \geq c \epsilon^{q}$ for all $\epsilon \in(0,2)$;

(ii) $q$-uniformly smooth if there exists a constant $k>0$ such that $\rho_{X}(\tau) \leq k \tau q$.

The generalized duality mapping $J_{q}: X \rightarrow 2^{X^{*}}$ is defined by

$$
J_{q}(x)=\left\{j_{q}(x) \in X^{*}:\left\langle j_{q}(x), x\right\rangle=\|x\|^{q},\left\|j_{q}(x)\right\|=\|x\|^{q-1}\right\} .
$$

In particular, $J=J_{2}$ is called the normalized duality mapping. It is well known that $J_{q}$ has the following properties: (a) $J_{q}$ is bounded; (b) if $X$ is smooth, then $J_{q}$ is single-valued; (c) if $X$ is strictly convex, then $J_{q}$ is one-to-one and strictly monotone.

Lemma 5.1 (see [18]). Let $X$ be a q-uniformly smooth Banach space. Then there exists a constant $L_{q}>0$ such that

$$
\left\|J_{q}(x)-J_{q}(y)\right\| \leq L_{q}\|x-y\|^{q-1}, \quad \forall x, y \in X .
$$

Lemma 5.2 (see [18]). Let $X$ be a q-uniformly convex Banach space. Then there exists a constant $K_{q}>0$ such that

$$
\left\langle J_{q}(x)-J_{q}(y), x-y\right\rangle \geq K_{q}\|x-y\|^{q}, \quad \forall x, y \in X .
$$

Lemma 5.3 (see [10]). Let $X$ be a q-uniformly convex Banach space and $M: X \rightarrow 2^{X^{*}}$ be a maximal monotone operator. Then for every $\lambda>0,\left(J_{q}+\lambda M\right)^{-1}$ is well-defined and singlevalued. 
We denote $\Pi_{\lambda}^{\phi(\cdot, x)}=\left(J_{q}+\lambda \partial \phi(\cdot, x)\right)^{-1}$ for each $x \in X$. By the definition of $\Pi_{\lambda}^{\phi(\cdot, x)}$ and Lemma 5.3, it is easy to prove the following proposition.

Proposition 5.1. Let $X$ be a q-uniformly convex Banach space, and $K$ be a nonempty, closed and convex subset of $X$. Let $g: X \rightarrow X$ be a single-valued mapping, $N: X^{*} \times X^{*} \rightarrow X^{*}$ be a single-valued mapping, and $F, E: X \rightarrow 2^{X^{*}}$ be two nonempty set-valued mappings. Let $\phi: X \times$ $X \rightarrow \mathbf{R} \cup\{+\infty\}$ be such that for each $x \in X, \phi(\cdot, x)$ is a proper, convex and lower semicontinuous functional. Then the following conclusions are equivalent:

(i) $x$ solves $\operatorname{CGMVI}(N(F, E), g, \phi, K)$;

(ii) $x$ solves the fixed-point problem $\mathrm{FP}\left(I-g+\Pi_{\lambda}^{\phi+\delta_{k}}\left(J_{q} \circ g-\lambda N(F, E)\right), K\right)$ :

find $x \in K$ such that $g(x) \in \Pi_{\lambda}^{\phi(\cdot, x)+\delta_{k}}\left(J_{q}(g(x))-\lambda N(F(x), E(x))\right)$.

Definition 5.2. A sequence $\left\{x_{n}\right\} \subset K$ is called a LP approximating sequence for $\operatorname{FP}(T, g, K)$ if there exists $w_{n} \in X$ with $w_{n} \rightarrow 0$ such that $g\left(x_{n}\right)+w_{n} \in K$, and there exists $y_{n} \in T\left(x_{n}, g\left(x_{n}\right)\right)$ such that $\left\|x_{n}-y_{n}\right\| \rightarrow 0$ as $n \rightarrow \infty$.

Definition 5.3. We say that $\operatorname{FP}(T, g, K)$ is strongly (resp. weakly) LP well-posed if it has a unique solution and every LP approximating sequence for $\mathrm{FP}(T, g, K)$ converges strongly (resp. weakly) to the unique solution. $\operatorname{FP}(T, g, K)$ is said to be strongly (resp. weakly) LP well-posed in the generalized sense if the solution set $S$ of $\mathrm{FP}(T, g, K)$ is nonempty and every LP approximating sequence has a subsequence which converges strongly (resp. weakly) to a point of $S$.

Remark 5.1. When $g=I$, Definitions 5.2 and 5.3 coincide with the Definitions 5.2 and 5.3 in [19], respectively.

Theorem 5.1. Let $X$ be a s-uniformly convex and $q$-uniformly smooth Banach space and $K$ be a nonempty, compact and convex subset of $X$. Let $F, E: X \rightarrow 2^{X^{*}}$ be nonempty compactvalued mappings which both are $\mathscr{H}$-continuous. Let $g: X \rightarrow X$ be a continuous mapping and $N: X^{*} \times X^{*} \rightarrow X^{*}$ be mixed Lipschitz continuous with respect to the first and second arguments. Assume that $\phi: X \times X \rightarrow \mathbf{R} \cup\{+\infty\}$ satisfies the conditions:

(C1) $\phi$ is proper, convex and lower semicontinuous in the first argument;

(C2) $\phi$ is upper semicontinuous in the second argument;

(C3) $\liminf _{n \rightarrow \infty} \inf _{y \in \operatorname{dom} \phi\left(\cdot, x_{n}\right)}\left(\phi\left(y, x_{n}\right)-\phi(y, \bar{x})\right) \geq 0, \quad \forall\left\{x_{n}\right\} \subset K: x_{n} \rightarrow \bar{x}(n \rightarrow \infty)$.

IfCGMVI $(N(F, E), g, \phi, K)$ is strongly LP well-posed, then $\mathrm{FP}\left(I-g+\Pi_{\lambda}^{\phi+\delta_{k}}\left(J_{q} \circ g-\lambda N(F, E)\right), K\right)$ is strongly LP well-posed, where $\lambda>0$ is a constant. 
Proof. We suppose that CGMVI $(N(F, E), g, \phi, K)$ is strongly LP well-posed and $x^{*}$ is the unique solution of CGMVI $(N(F, E), g, \phi, K)$. By Proposition 5.1, $x^{*}$ is the unique solution of $\mathrm{FP}(I-g+$ $\left.\Pi_{\lambda}^{\phi+\delta_{k}}\left(J_{q} \circ g-\lambda N(F, E)\right), K\right)$. Let $\left\{x_{n}\right\}$ be a LP approximating sequence for $\operatorname{FP}\left(I-g+\Pi_{\lambda}^{\phi+\delta_{k}}\left(J_{q} \circ\right.\right.$ $g-\lambda N(F, E)), K)$, then there exists $w_{n} \in X$ with $w_{n} \rightarrow 0$ such that $g\left(x_{n}\right)+w_{n} \in K$, and there exists $y_{n} \in(I-g)\left(x_{n}\right)+\Pi_{\lambda}^{\phi\left(\cdot, x_{n}\right)+\delta_{k}}\left(J_{q}\left(g\left(x_{n}\right)\right)-\lambda N\left(F\left(x_{n}\right), E\left(x_{n}\right)\right)\right)$ such that $\left\|x_{n}-y_{n}\right\| \rightarrow 0$ as $n \rightarrow \infty$. By the definition of $\Pi_{\lambda}^{\phi\left(\cdot, x_{n}\right)+\delta_{k}}$, there exist $u_{n} \in F\left(x_{n}\right)$ and $v_{n} \in E\left(x_{n}\right)$ such that

$$
\frac{J_{q}\left(g\left(x_{n}\right)\right)-J_{q}\left(y_{n}-x_{n}+g\left(x_{n}\right)\right)}{\lambda}-N\left(u_{n}, v_{n}\right) \in \partial\left(\phi\left(\cdot, x_{n}\right)+\delta_{k}\right)\left(y_{n}-x_{n}+g\left(x_{n}\right)\right) .
$$

It is easy to see that $\left\{y_{n}-x_{n}+g\left(x_{n}\right)\right\} \subset K$ and

$$
\begin{aligned}
& \left\langle\frac{J_{q}\left(g\left(x_{n}\right)\right)-J_{q}\left(y_{n}-x_{n}+g\left(x_{n}\right)\right)}{\lambda}-N\left(u_{n}, v_{n}\right), y-\left(y_{n}-x_{n}+g\left(x_{n}\right)\right)\right\rangle \\
& \quad \leq \phi\left(y, x_{n}\right)-\phi\left(y_{n}-x_{n}+g\left(x_{n}\right), x_{n}\right), \quad \forall y \in K, n \geq 1 .
\end{aligned}
$$

Putting $z_{n}=\frac{J_{q}\left(g\left(x_{n}\right)\right)-J_{q}\left(y_{n}-x_{n}+g\left(x_{n}\right)\right)}{\lambda}$, by Lemma 5.1 we deduce from $\left\|x_{n}-y_{n}\right\| \rightarrow 0$ that as $n \rightarrow$ $\infty$,

$$
\left\|z_{n}\right\|=\left\|\frac{J_{q}\left(g\left(x_{n}\right)\right)-J_{q}\left(y_{n}-x_{n}+g\left(x_{n}\right)\right)}{\lambda}\right\| \leq \frac{L_{q}\left\|y_{n}-x_{n}\right\|^{q-1}}{\lambda} \rightarrow 0 .
$$

Let $\left\{x_{n_{i}}\right\}$ be any subsequence of $\left\{x_{n}\right\}$ such that $x_{n_{i}} \rightarrow \bar{x}$ as $i \rightarrow \infty$. Clearly $\bar{x} \in K$. Since $\left\{y_{n}-x_{n}+g\left(x_{n}\right)\right\} \subset K$ and $g$ is continuous, we know that $g(\bar{x}) \in K$. So, it follows from (5.1), (5.2) and conditions $(\mathrm{C} 1)-(\mathrm{C} 3)$ that

$$
\begin{aligned}
& \liminf _{i \rightarrow \infty}\left(\phi\left(y_{n_{i}}-x_{n_{i}}+g\left(x_{n_{i}}\right), x_{n_{i}}\right)-\phi\left(y_{n_{i}}-x_{n_{i}}+g\left(x_{n_{i}}\right), \bar{x}\right)\right) \\
& \quad \geq \liminf _{i \rightarrow \infty} \inf _{y \in \operatorname{dom} \phi\left(\cdot, x_{n_{i}}\right)}\left(\phi\left(y, x_{n_{i}}\right)-\phi(y, \bar{x})\right) \geq 0
\end{aligned}
$$

and

$$
\begin{aligned}
& \liminf _{i \rightarrow \infty}\left\langle N\left(u_{n_{i}}, v_{n_{i}}\right), y_{n_{i}}-x_{n_{i}}+g\left(x_{n_{i}}\right)-y\right\rangle+\phi(g(\bar{x}), \bar{x})-\phi(y, \bar{x}) \\
& \leq \liminf _{i \rightarrow \infty}\left\langle N\left(u_{n_{i}}, v_{n_{i}}\right)-z_{n_{i}}, y_{n_{i}}-x_{n_{i}}+g\left(x_{n_{i}}\right)-y\right\rangle+\liminf _{i \rightarrow \infty} \phi\left(y_{n_{i}}-x_{n_{i}}+g\left(x_{n_{i}}\right), \bar{x}\right) \\
& \quad+\liminf _{i \rightarrow \infty}\left(\phi\left(y_{n_{i}}-x_{n_{i}}+g\left(x_{n_{i}}\right), x_{n_{i}}\right)-\phi\left(y_{n_{i}}-x_{n_{i}}+g\left(x_{n_{i}}\right), \bar{x}\right)\right)+\liminf _{i \rightarrow \infty}\left(-\phi\left(y, x_{n_{i}}\right)\right) \\
& \leq \liminf _{i \rightarrow \infty}\left\{\left\langle N\left(u_{n_{i}}, v_{n_{i}}\right)-z_{n_{i}}, y_{n_{i}}-x_{n_{i}}+g\left(x_{n_{i}}\right)-y\right\rangle+\phi\left(y_{n_{i}}-x_{n_{i}}+g\left(x_{n_{i}}\right), \bar{x}\right)\right. \\
& \left.\quad+\phi\left(y_{n_{i}}-x_{n_{i}}+g\left(x_{n_{i}}\right), x_{n_{i}}\right)-\phi\left(y_{n_{i}}-x_{n_{i}}+g\left(x_{n_{i}}\right), \bar{x}\right)-\phi\left(y, x_{n_{i}}\right)\right\} \\
& =\liminf _{i \rightarrow \infty}\left\{\left\langle N\left(u_{n_{i}}, v_{n_{i}}\right)-z_{n_{i}}, y_{n_{i}}-x_{n_{i}}+g\left(x_{n_{i}}\right)-y\right\rangle+\phi\left(y_{n_{i}}-x_{n_{i}}+g\left(x_{n_{i}}\right), x_{n_{i}}\right)-\phi\left(y, x_{n_{i}}\right)\right\} \\
& \leq 0 .
\end{aligned}
$$

Since $F$ and $E$ are nonempty compact-valued mappings, in terms of Lemma 2.1, for each $u_{n} \in F\left(x_{n}\right)$ and $v_{n} \in E\left(x_{n}\right)$ there exist $\bar{u}_{n} \in F(\bar{x})$ and $\bar{v}_{n} \in E(\bar{x})$ such that $\left\|u_{n}-\bar{u}_{n}\right\| \leq \mathscr{H}\left(F\left(x_{n}\right)\right.$, $F(\bar{x}))$ and $\left\|v_{n}-\bar{v}_{n}\right\| \leq \mathscr{H}\left(E\left(x_{n}\right), E(\bar{x})\right)$. Since $F$ and $E$ both are $\mathscr{H}$-continuous, one deduces that $\left\|u_{n_{i}}-\bar{u}_{n_{i}}\right\| \leq \mathscr{H}\left(F\left(x_{n_{i}}\right), F(\bar{x})\right) \rightarrow 0$ and $\left\|v_{n_{i}}-\bar{v}_{n_{i}}\right\| \leq \mathscr{H}\left(E\left(x_{n_{i}}\right), E(\bar{x})\right) \rightarrow 0$ as $i \rightarrow \infty$. Since 
$F(\bar{x})$ and $E(\bar{x})$ both are compact, without loss of generality we may assume that $\bar{u}_{n_{i}} \rightarrow \bar{u} \in F(\bar{x})$ and $\bar{v}_{n_{i}} \rightarrow \bar{v} \in E(\bar{x})$ as $i \rightarrow \infty$. Thus, we conclude that

$$
\left\|u_{n_{i}}-\bar{u}\right\| \leq\left\|u_{n_{i}}-\bar{u}_{n_{i}}\right\|+\left\|\bar{u}_{n_{i}}-\bar{u}\right\| \rightarrow 0 \quad \text { as } i \rightarrow \infty,
$$

and

$$
\left\|v_{n_{i}}-\bar{v}\right\| \leq\left\|v_{n_{i}}-\bar{v}_{n_{i}}\right\|+\left\|\bar{v}_{n_{i}}-\bar{v}\right\| \rightarrow 0 \quad \text { as } i \rightarrow \infty .
$$

That is, $u_{n_{i}} \rightarrow \bar{u}$ and $v_{n_{i}} \rightarrow \bar{v}$ as $i \rightarrow \infty$. Note that $N$ is mixed Lipschitz continuous with respect to the first and second arguments. Hence there exists a pair of constants $\zeta, \xi>0$ such that

$$
\left\|N\left(u_{n_{i}}, v_{n_{i}}\right)-N(\bar{u}, \bar{v})\right\| \leq \zeta\left\|u_{n_{i}}-\bar{u}\right\|+\xi\left\|v_{n_{i}}-\bar{v}\right\| \rightarrow 0 \quad \text { as } i \rightarrow \infty
$$

This together with $u_{n_{i}} \rightarrow \bar{u}$ and $v_{n_{i}} \rightarrow \bar{v}$, implies that $N\left(u_{n_{i}}, v_{n_{i}}\right) \rightarrow N(\bar{u}, \bar{v})$ as $i \rightarrow \infty$. So, it immediately follows from (5.3) that

$$
\langle N(\bar{u}, \bar{v}), g(\bar{x})-y\rangle+\phi(g(\bar{x}), \bar{x})-\phi(y, \bar{x}) \leq 0, \quad \forall y \in K .
$$

Thus, $\bar{x}$ solves CGMVI $(N(F, E), g, \phi, K)$. Since CGMVI $(N(F, E), g, \phi, K)$ has a unique solution $x^{*}$, we get $\bar{x}=x^{*}$. This shows that $x_{n} \rightarrow x^{*}$ as $n \rightarrow \infty$. Therefore, $\operatorname{FP}\left(I-g+\Pi_{\lambda}^{\phi+\delta_{k}}\left(J_{q} \circ g-\right.\right.$ $\lambda N(F, E)), K)$ is strongly LP well-posed. The proof is complete.

Theorem 5.2. Let $X$ be a $q$-uniformly convex Banach space and $K$ be a nonempty, closed and convex subset of $X$. Let $F, E: X \rightarrow 2^{X^{*}}$ be nonempty compact-valued mappings which both are $\mathscr{H}$-uniformly continuous. Let $g: X \rightarrow X$ be a homeomorphic mapping and $N: X^{*} \times X^{*} \rightarrow X^{*}$ be mixed Lipschitz continuous with respect to the first and second arguments. Assume that $\phi: X \times X \rightarrow \mathbf{R} \cup\{+\infty\}$ satisfies the conditions:

(C1) for each $x \in X, \phi(\cdot, x)$ is a proper, convex and subdifferentiable functional;

(C2) $\left\|\Pi_{\lambda}^{\phi(\cdot, x)+\delta_{K}}\left(v^{*}\right)-\Pi_{\lambda}^{\phi(\cdot, y)+\delta_{K}}\left(v^{*}\right)\right\| \leq \beta\|g(x)-g(y)\|, \forall x, y \in X, v^{*} \in X^{*}$ for some $\beta>0$.

If $\mathrm{FP}\left(I-g+\Pi_{\lambda}^{\phi+\delta_{k}}\left(J_{q} \circ g-\lambda N(F, E)\right), K\right)$ is strongly LP well-posed, then CGMVI $(N(F, E), g, \phi, K)$ is strongly LP well-posed.

Proof. Let $\left\{x_{n}\right\} \subset K$ be a LP approximating sequence for CGMVI $(N(F, E), g, \phi, K)$. Then there exist $w_{n} \in X$ with $w_{n} \rightarrow 0$ and $0<\epsilon_{n} \rightarrow 0$ such that $g\left(x_{n}\right)+w_{n} \in K$, and there exist $u_{n} \in F\left(x_{n}\right)$ and $v_{n} \in E\left(x_{n}\right)$ satisfying

$$
\phi\left(g\left(x_{n}\right), x_{n}\right) \geq \phi\left(y, x_{n}\right)+\left\langle N\left(u_{n}, v_{n}\right), y-g\left(x_{n}\right)\right\rangle+\epsilon_{n}, \quad \forall y \in K, n \geq 1 .
$$

Since $g\left(x_{n}\right)+w_{n} \in K$, there exists $k_{n} \in K$ such that $g\left(x_{n}\right)+w_{n}=k_{n}$. Define $\tilde{\phi}_{n}: X \rightarrow \mathbf{R} \cup\{+\infty\}$ as follows:

$$
\tilde{\phi}_{n}(y)=\phi\left(y, x_{n}\right)+\left\langle N\left(u_{n}, v_{n}\right), y-g\left(x_{n}\right)\right\rangle, \quad \forall y \in K, n \geq 1 .
$$


Since $\phi$ is proper, convex and subdifferentiable in the first argument, then we have that $\tilde{\phi}_{n}$ is proper, convex and subdifferentiable for all $n \geq 1$. It follows from Proposition 2.2.6 of [16] that $\tilde{\phi}_{n}$ is Lipschitz continuous. Since $\left\|w_{n}\right\|=\left\|k_{n}-g\left(x_{n}\right)\right\| \rightarrow 0$, then there exists $0<\delta_{n} \rightarrow 0$ such that

$$
\tilde{\phi}_{n}\left(k_{n}\right)-\tilde{\phi}_{n}\left(g\left(x_{n}\right)\right) \leq \delta_{n} .
$$

It follows from (5.4) and (5.5) that

$$
\tilde{\phi}_{n}\left(k_{n}\right) \leq \tilde{\phi}_{n}(y)+\delta_{n}+\epsilon_{n}, \quad \forall y \in K .
$$

By Ekeland's theorem [17], there exists $\widetilde{x}_{n} \in K$ such that

$$
\left\|g\left(\widetilde{x}_{n}\right)-k_{n}\right\| \leq \sqrt{\delta_{n}+\epsilon_{n}}
$$

and

$$
\tilde{\phi}_{n}\left(g\left(\widetilde{x}_{n}\right)\right) \leq \tilde{\phi}_{n}(y)+\sqrt{\delta_{n}+\epsilon_{n}}\left\|y-g\left(\widetilde{x}_{n}\right)\right\|, \quad \forall y \in K .
$$

Thus, $g\left(\widetilde{x}_{n}\right)$ minimizes the function $\tilde{\phi}_{n}\left((\cdot)+\sqrt{\delta_{n}+\epsilon_{n}}\left\|\cdot-g\left(\widetilde{x}_{n}\right)\right\|\right.$. It follows that $0^{*} \in \partial\left(\tilde{\phi}_{n}((\cdot)+\right.$ $\left.\sqrt{\delta_{n}+\epsilon_{n}}\left\|\cdot-g\left(\widetilde{x}_{n}\right)\right\|\right)\left(g\left(\widetilde{x}_{n}\right)\right)$. That is,

$$
0^{*} \in \partial \tilde{\phi}_{n}\left(g\left(\widetilde{x}_{n}\right)\right)+\sqrt{\delta_{n}+\epsilon_{n}} B_{X^{*}}
$$

So there exists

$$
x_{n}^{*} \in \partial \tilde{\phi}_{n}\left(g\left(\widetilde{x}_{n}\right)\right)=\partial \phi_{1}\left(g\left(\widetilde{x}_{n}\right), x_{n}\right)+N\left(u_{n}, v_{n}\right)
$$

such that

$$
\left\|x_{n}^{*}\right\| \leq \sqrt{\delta_{n}+\epsilon_{n}}
$$

It follows from (5.6) that

$$
g\left(\widetilde{x}_{n}\right)=\Pi_{\lambda}^{\phi\left(\cdot, x_{n}\right)+\delta_{K}}\left(J_{q}\left(g\left(\widetilde{x}_{n}\right)\right)+\lambda x_{n}^{*}-\lambda N\left(u_{n}, v_{n}\right)\right) .
$$

Since $\left\|g\left(x_{n}\right)-k_{n}\right\| \rightarrow 0$ and $\left\|g\left(\widetilde{x}_{n}\right)-k_{n}\right\| \rightarrow 0$, we have $\left\|g\left(x_{n}\right)-g\left(\widetilde{x}_{n}\right)\right\| \leq\left\|g\left(x_{n}\right)-k_{n}\right\|+\| g\left(\widetilde{x}_{n}\right)-$ $k_{n} \| \rightarrow 0$. Since $F, E: X \rightarrow 2^{X^{*}}$ are nonempty compact-valued mappings which both are $\mathscr{H}$ uniformly continuous, in terms of Lemma 2.1 we know that for each $u_{n} \in F\left(x_{n}\right)$ and $v_{n} \in$ $E\left(x_{n}\right)$ there exist $\widetilde{u}_{n} \in F\left(\widetilde{x}_{n}\right)$ and $\widetilde{v}_{n} \in E\left(\widetilde{x}_{n}\right)$ such that $\left\|u_{n}-\widetilde{u}_{n}\right\| \leq \mathscr{H}\left(F\left(x_{n}\right), F\left(\widetilde{x}_{n}\right)\right) \rightarrow 0$ and $\left\|v_{n}-\widetilde{v}_{n}\right\| \leq \mathscr{H}\left(E\left(x_{n}\right), E\left(\widetilde{x}_{n}\right)\right) \rightarrow 0$ as $n \rightarrow \infty$. Note that $N$ is mixed Lipschitz continuous with respect to the first and second arguments. Hence, it follows that there exists a pair of constants $\zeta, \xi>0$ such that

$$
\left\|N\left(u_{n}, v_{n}\right)-N\left(\widetilde{u}_{n}, \widetilde{v}_{n}\right)\right\| \leq \zeta\left\|u_{n}-\widetilde{u}_{n}\right\|+\xi\left\|v_{n}-\widetilde{v}_{n}\right\| \rightarrow 0
$$

as $n \rightarrow \infty$. Since

$$
\Pi_{\lambda}^{\phi\left(\cdot, \widetilde{x}_{n}\right)+\delta_{K}}\left(J_{q}\left(g\left(\widetilde{x}_{n}\right)\right)-\lambda N\left(\widetilde{u}_{n}, \widetilde{v}_{n}\right)\right) \in \Pi_{\lambda}^{\phi\left(\cdot, \widetilde{x}_{n}\right)+\delta_{K}}\left(J_{q}\left(g\left(\widetilde{x}_{n}\right)\right)-\lambda N\left(F\left(\widetilde{x}_{n}\right), E\left(\widetilde{x}_{n}\right)\right)\right),
$$


and as $n \rightarrow \infty$,

$$
\begin{aligned}
\| & g\left(\widetilde{x}_{n}\right)-\Pi_{\lambda}^{\phi\left(\cdot, \widetilde{x}_{n}\right)+\delta_{K}}\left(J_{q}\left(g\left(\widetilde{x}_{n}\right)\right)-\lambda N\left(\widetilde{u}_{n}, \widetilde{v}_{n}\right)\right) \| \\
= & \left\|\Pi_{\lambda}^{\phi\left(\cdot, x_{n}\right)+\delta_{K}}\left(J_{q}\left(g\left(\widetilde{x}_{n}\right)\right)+\lambda x_{n}^{*}-\lambda N\left(u_{n}, v_{n}\right)\right)-\Pi_{\lambda}^{\phi\left(\cdot, \widetilde{x}_{n}\right)+\delta_{K}}\left(J_{q}\left(g\left(\widetilde{x}_{n}\right)\right)-\lambda N\left(\widetilde{u}_{n}, \widetilde{v}_{n}\right)\right)\right\| \\
\leq & \left\|\Pi_{\lambda}^{\phi\left(\cdot, x_{n}\right)+\delta_{K}}\left(J_{q}\left(g\left(\widetilde{x}_{n}\right)\right)+\lambda x_{n}^{*}-\lambda N\left(u_{n}, v_{n}\right)\right)-\Pi_{\lambda}^{\phi\left(\cdot, \widetilde{x}_{n}\right)+\delta_{K}}\left(J_{q}\left(g\left(\widetilde{x}_{n}\right)\right)+\lambda x_{n}^{*}-\lambda N\left(u_{n}, v_{n}\right)\right)\right\| \\
& +\left\|\Pi_{\lambda}^{\phi\left(\cdot, \widetilde{x}_{n}\right)+\delta_{K}}\left(J_{q}\left(g\left(\widetilde{x}_{n}\right)\right)+\lambda x_{n}^{*}-\lambda N\left(u_{n}, v_{n}\right)\right)-\Pi_{\lambda}^{\phi\left(\cdot, \widetilde{x}_{n}\right)+\delta_{K}}\left(J_{q}\left(g\left(\widetilde{x}_{n}\right)\right)-\lambda N\left(\widetilde{u}_{n}, \widetilde{v}_{n}\right)\right)\right\| \\
\leq & \beta\left\|g\left(x_{n}\right)-g\left(\widetilde{x}_{n}\right)\right\|+\left\|\left(J_{q}\left(g\left(\widetilde{x}_{n}\right)\right)+\lambda x_{n}^{*}-\lambda N\left(u_{n}, v_{n}\right)\right)-\left(J_{q}\left(g\left(\widetilde{x}_{n}\right)\right)-\lambda N\left(\widetilde{u}_{n}, \widetilde{v}_{n}\right)\right)\right\| \\
= & \beta\left\|g\left(x_{n}\right)-g\left(\widetilde{x}_{n}\right)\right\|+\left\|\lambda x_{n}^{*}+\lambda\left(N\left(\widetilde{u}_{n}, \widetilde{v}_{n}\right)-N\left(u_{n}, v_{n}\right)\right)\right\| \\
\leq & \beta\left\|g\left(x_{n}\right)-g\left(\widetilde{x}_{n}\right)\right\|+\left\|\lambda x_{n}^{*}\right\|+\left\|\lambda\left(N\left(\widetilde{u}_{n}, \widetilde{v}_{n}\right)-N\left(u_{n}, v_{n}\right)\right)\right\| \rightarrow 0,
\end{aligned}
$$

this shows that

$$
\lim _{n \rightarrow \infty}\left\|\widetilde{x}_{n}-\left[(I-g)\left(\widetilde{x}_{n}\right)+\Pi_{\lambda}^{\phi\left(\cdot, \widetilde{x}_{n}\right)+\delta_{K}}\left(J_{q}\left(g\left(\widetilde{x}_{n}\right)\right)-\lambda N\left(\widetilde{u}_{n}, \widetilde{v}_{n}\right)\right)\right]\right\|=0
$$

Thus, $\left\{\widetilde{x}_{n}\right\}$ is a LP approximating sequence for $\operatorname{FP}\left(I-g+\Pi_{\lambda}^{\phi+\delta_{k}}\left(J_{q} \circ g-\lambda N(F, E)\right), K\right)$. Let $x^{*}$ be the unique solution of $\operatorname{CGMVI}(N(F, E), g, \phi, K)$. By Proposition 5.1 , we obtain that $x^{*}$ is also the unique solution of $\operatorname{FP}\left(I-g+\Pi_{\lambda}^{\phi+\delta_{k}}\left(J_{q} \circ g-\lambda N(F, E)\right), K\right)$. If $\operatorname{FP}\left(I-g+\Pi_{\lambda}^{\phi+\delta_{k}}\left(J_{q} \circ g-\right.\right.$ $\lambda N(F, E)), K)$ is strongly LP well-posed, then $\widetilde{x}_{n} \rightarrow x^{*}$. It follows that

$$
\left\|g\left(x_{n}\right)-g\left(x^{*}\right)\right\| \leq\left\|g\left(x_{n}\right)-g\left(\widetilde{x}_{n}\right)\right\|+\left\|g\left(\widetilde{x}_{n}\right)-g\left(x^{*}\right)\right\| \rightarrow 0 .
$$

Since $g$ is a homeomorphic mapping, we immediately obtain that $x_{n} \rightarrow x^{*}$ as $n \rightarrow \infty$. Thus, $\operatorname{CGMVI}(N(F, E), g, \phi, K)$ is strongly LP well-posed.

Theorem 5.3. Let $X$ be a s-uniformly convex and $q$-uniformly smooth Banach space and $K$ be a nonempty, compact and convex subset of $X$. Let $F, E: X \rightarrow 2^{X^{*}}$ be nonempty compactvalued mappings such that $F(K) \cup E(K)$ is bounded. Let $g: X \rightarrow X$ be a continuous mapping and $N: X^{*} \times X^{*} \rightarrow X^{*}$ be be mixed Lipschitz continuous with respect to the first and second arguments. Assume that $\phi: X \times X \rightarrow \mathbf{R} \cup\{+\infty\}$ satisfies the conditions:

(C1) $\phi$ is proper, convex and lower semicontinuous in the first argument;

(C2) $\lim _{n \rightarrow \infty}\left|\phi\left(e_{n}+g\left(x_{n}\right), x_{n}\right)-\phi\left(g\left(x_{n}\right), x_{n}\right)\right|=0, \forall\left\{x_{n}\right\} \subset K:\left\{e_{n}+g\left(x_{n}\right)\right\} \subset K$ with $e_{n} \rightarrow 0$. If CGMVI $(N(F, E), g, \phi, K)$ is strongly (resp. weakly) LP $\frac{1}{\lambda}$-well-posed in the generalized sense, then $\mathrm{FP}\left(I-g+\Pi_{\lambda}^{\phi+\delta_{k}}\left(J_{q} \circ g-\lambda N(F, E)\right), K\right)$ is strongly (resp. weakly) LP well-posed in the generalized sense.

Proof. Let $\left\{x_{n}\right\} \subset K$ be a LP approximating sequence for $\mathrm{FP}\left(I-g+\Pi_{\lambda}^{\phi+\delta_{k}}\left(J_{q} \circ g-\lambda N(F, E)\right), K\right)$. Then there exists $w_{n} \in X$ with $w_{n} \rightarrow 0$ such that $g\left(x_{n}\right)+w_{n} \in K$, and there exists $y_{n} \in(I-$ $g)\left(x_{n}\right)+\Pi_{\lambda}^{\phi\left(\cdot, x_{n}\right)+\delta_{k}}\left(J_{q}\left(g\left(x_{n}\right)\right)-\lambda N\left(F\left(x_{n}\right), E\left(x_{n}\right)\right)\right)$ such that $\left\|x_{n}-y_{n}\right\| \rightarrow 0$ as $n \rightarrow \infty$. By the 
definition of $\Pi_{\lambda}^{\phi\left(\cdot, x_{n}\right)+\delta_{k}}$, we know that $\left\{y_{n}-x_{n}+g\left(x_{n}\right)\right\} \subset K$ and there exist $u_{n} \in F\left(x_{n}\right)$ and $v_{n} \in E\left(x_{n}\right)$ such that

$$
\begin{aligned}
& \left\langle\frac{J_{q}\left(g\left(x_{n}\right)\right)-J_{q}\left(y_{n}-x_{n}+g\left(x_{n}\right)\right)}{\lambda}-N\left(u_{n}, v_{n}\right), y-\left(y_{n}-x_{n}+g\left(x_{n}\right)\right)\right\rangle \\
& \quad \leq \phi\left(y, x_{n}\right)-\phi\left(y_{n}-x_{n}+g\left(x_{n}\right), x_{n}\right), \quad \forall y \in K, n \geq 1 .
\end{aligned}
$$

It follows from (5.8) that for any $y \in K$,

$$
\begin{aligned}
\langle N & \left.\left(u_{n}, v_{n}\right), g\left(x_{n}\right)-y\right\rangle+\phi\left(g\left(x_{n}\right), x_{n}\right)-\phi\left(y, x_{n}\right) \\
\leq & \left\langle N\left(u_{n}, v_{n}\right), x_{n}-y_{n}\right\rangle+\phi\left(g\left(x_{n}\right), x_{n}\right)-\phi\left(y_{n}-x_{n}+g\left(x_{n}\right), x_{n}\right) \\
& +\left\langle\frac{J_{q}\left(g\left(x_{n}\right)\right)-J_{q}\left(y_{n}-x_{n}+g\left(x_{n}\right)\right)}{\lambda}, g\left(x_{n}\right)-y\right\rangle+\left\langle\frac{J_{q}\left(g\left(x_{n}\right)\right)-J_{q}\left(y_{n}-x_{n}+g\left(x_{n}\right)\right)}{\lambda}, y_{n}-x_{n}\right\rangle \\
\leq & \left\|N\left(u_{n}, v_{n}\right)\right\|\left\|x_{n}-y_{n}\right\|+\left|\phi\left(g\left(x_{n}\right), x_{n}\right)-\phi\left(y_{n}-x_{n}+g\left(x_{n}\right), x_{n}\right)\right| \\
& +\frac{\left\|J_{q}\left(g\left(x_{n}\right)\right)-J_{q}\left(y_{n}-x_{n}+g\left(x_{n}\right)\right)\right\|}{\lambda}\left\|g\left(x_{n}\right)-y\right\|+\frac{\left\|J_{q}\left(g\left(x_{n}\right)\right)-J_{q}\left(y_{n}-x_{n}+g\left(x_{n}\right)\right)\right\|}{\lambda}\left\|y_{n}-x_{n}\right\| \\
\leq & \left\|N\left(u_{n}, v_{n}\right)\right\|\left\|x_{n}-y_{n}\right\|+\left|\phi\left(g\left(x_{n}\right), x_{n}\right)-\phi\left(y_{n}-x_{n}+g\left(x_{n}\right), x_{n}\right)\right| \\
& +\frac{1}{2 \lambda}\left\|J_{q}\left(g\left(x_{n}\right)\right)-J_{q}\left(y_{n}-x_{n}+g\left(x_{n}\right)\right)\right\|^{2}+\frac{1}{2 \lambda}\left\|g\left(x_{n}\right)-y\right\|^{2} \\
& +\frac{\left\|J_{q}\left(g\left(x_{n}\right)\right)-J_{q}\left(y_{n}-x_{n}+g\left(x_{n}\right)\right)\right\|}{\lambda}\left\|y_{n}-x_{n}\right\| \\
= & \frac{1}{2 \lambda}\left\|g\left(x_{n}\right)-y\right\|^{2}+\left[\left\|N\left(u_{n}, v_{n}\right)\right\|+\frac{1}{\lambda}\left\|J_{q}\left(g\left(x_{n}\right)\right)-J_{q}\left(y_{n}-x_{n}+g\left(x_{n}\right)\right)\right\|\right]\left\|y_{n}-x_{n}\right\| \\
& +\left|\phi\left(g\left(x_{n}\right), x_{n}\right)-\phi\left(y_{n}-x_{n}+g\left(x_{n}\right), x_{n}\right)\right|+\frac{1}{2 \lambda}\left\|J_{q}\left(g\left(x_{n}\right)\right)-J_{q}\left(y_{n}-x_{n}+g\left(x_{n}\right)\right)\right\|^{2} .
\end{aligned}
$$

Since $N$ is mixed Lipschitz continuous with respect to the first and second arguments, there exists a pair of constants $\zeta, \xi>0$ such that

$$
\left\|N\left(x_{1}, y_{1}\right)-N\left(x_{2}, y_{2}\right)\right\| \leq \zeta\left\|x_{1}-x_{2}\right\|+\xi\left\|y_{1}-y_{2}\right\|, \quad \forall\left(x_{i}, y_{i}\right) \in X \times X, i=1,2,
$$

which together with $\left(u_{n}, v_{n}\right) \in F(K) \times E(K)$ and the boundedness of $F(K) \cup E(K)$, implies that $\left\{N\left(u_{n}, v_{n}\right)\right\}$ is bounded. Putting $e_{n}=y_{n}-x_{n}$, from condition (C2) we get

$$
\lim _{n \rightarrow \infty}\left|\phi\left(y_{n}-x_{n}+g\left(x_{n}\right), x_{n}\right)-\phi\left(g\left(x_{n}\right), x_{n}\right)\right|=\lim _{n \rightarrow \infty}\left|\phi\left(e_{n}+g\left(x_{n}\right), x_{n}\right)-\phi\left(g\left(x_{n}\right), x_{n}\right)\right|=0 .
$$

Again, by Lemma 5.1 we have

$$
\left\|J_{q}\left(y_{n}-x_{n}+g\left(x_{n}\right)\right)-J_{q}\left(g\left(x_{n}\right)\right)\right\| \leq L_{q}\left\|y_{n}-x_{n}\right\|^{q-1} \rightarrow 0 \text {. }
$$

It follows from (5.9) that $\left\{x_{n}\right\}$ is a LP $\frac{1}{\lambda}$-approximating sequence for CGMVI $(N(F, E), g, \phi, K)$. If $\operatorname{CGMVI}(N(F, E), g, \phi, K)$ is strongly LP $\frac{1}{\lambda}$-well-posed in the generalized sense, then $\left\{x_{n}\right\}$ has a subsequence $\left\{x_{n_{i}}\right\}$ such that $x_{n_{i}} \rightarrow x^{*}$ as $i \rightarrow \infty$, where $x^{*}$ is a solution of CGMVI $(N(F, E), g, \phi$, $K)$. By Proposition 5.1, we obtain that $x^{*}$ is also a solution of $\mathrm{FP}\left(I-g+\Pi_{\lambda}^{\phi+\delta_{k}}\left(J_{q} \circ g-\lambda N(F, E)\right)\right.$, 
$K)$. Thus, $\operatorname{FP}\left(I-g+\Pi_{\lambda}^{\phi+\delta_{k}}\left(J_{q} \circ g-\lambda N(F, E)\right), K\right)$ is strongly LP well-posed in the generalized sense.

If CGMVI $(N(F, E), g, \phi, K)$ is weakly LP $\frac{1}{\lambda}$-well-posed in the generalized sense, then $\left\{x_{n}\right\}$ has a subsequence $\left\{x_{n_{i}}\right\}$ such that $x_{n_{i}} \rightarrow x^{*}$ as $i \rightarrow \infty$, where $x^{*}$ is a solution of $\operatorname{CGMVI}(N(F, E)$, $g, \phi, K)$. By Proposition 5.1, we obtain that $x^{*}$ is also a solution of $\operatorname{FP}\left(I-g+\Pi_{\lambda}^{\phi+\delta_{k}}\left(J_{q} \circ g-\right.\right.$ $\lambda N(F, E)), K)$. Thus, $\mathrm{FP}\left(I-g+\Pi_{\lambda}^{\phi+\delta_{k}}\left(J_{q} \circ g-\lambda N(F, E)\right), K\right)$ is weakly LP well-posed in the generalized sense.

Theorem 5.4. Let $X$ be a q-uniformly convex Banach space and $K$ be a nonempty, closed and convex subset of $X$. Let $F, E: X \rightarrow 2^{X^{*}}$ be nonempty compact-valued mappings which both are $\mathscr{H}$-uniformly continuous. Let $g: X \rightarrow X$ be a homeomorphic mapping and $N: X^{*} \times X^{*} \rightarrow X^{*}$ be mixed Lipschitz continuous with respect to the first and second arguments. Assume that $\phi: X \times X \rightarrow \mathbf{R} \cup\{+\infty\}$ satisfies the conditions:

(C1) for each $x \in X, \phi(\cdot, x)$ is a proper, convex and subdifferentiable functional;

(C2) $\left\|\Pi_{\lambda}^{\phi(\cdot, x)+\delta_{K}}\left(v^{*}\right)-\Pi_{\lambda}^{\phi(\cdot, y)+\delta_{K}}\left(v^{*}\right)\right\| \leq \beta\|g(x)-g(y)\|, \forall x, y \in X, v^{*} \in X^{*}$ for some $\beta>0$.

If $\mathrm{FP}\left(I-g+\Pi_{\lambda}^{\phi+\delta_{k}}\left(J_{q} \circ g-\lambda N(F, E)\right), K\right)$ is strongly LP well-posed in the generalized sense, then $\operatorname{CGMVI}(N(F, E), g, \phi, K)$ is strongly LP well-posed in the generalized sense, where $\lambda>0$ is a constant.

Proof. The conclusion follows from the similar arguments to those in the proof of Theorem 5.2 .

Remark 5.2. Our Theorems 5.1-5.4 improve, extend and develop Theorems 5.1-5.4 in [19] to a great extent because our CGMVI $(N(F, E), g, \phi, K)$ and $\operatorname{FP}\left(I-g+\Pi_{\lambda}^{\phi+\delta_{k}}\left(J_{q} \circ g-\lambda N(F, E)\right), K\right)$ are more general than the $\operatorname{GMVI}(F, \phi, K)$ and $\operatorname{FP}\left(\Pi_{\lambda}^{\phi+\delta_{k}}\left(J_{q}-\lambda F, K\right)\right.$ in [19], respectively.

\section{Conditions for Levitin-Polyak Well-Posedness}

In this section, we shall derive some conditions under which a completely generalized mixed variational inequality in Banach spaces is Levitin-Polyak well-posed.

Theorem 6.1. Let $K$ be a nonempty, compact and convex subset of $X$. Let $F, E: X \rightarrow 2^{X^{*}}$ be nonempty compact-valued mappings which both are $\mathscr{H}$-continuous. Let $g: X \rightarrow X$ be a continuous mapping and $N: X^{*} \times X^{*} \rightarrow X^{*}$ be mixed Lipschitz continuous with respect to the first and second arguments. Assume that $\phi: X \times X \rightarrow \mathbf{R} \cup\{+\infty\}$ satisfies the conditions:

(C1) $\phi$ is proper, convex and lower semicontinuous in the first argument;

(C2) $\phi$ is upper semicontinuous in the second argument; 
(C3) $\liminf _{n \rightarrow \infty} \inf _{y \in \operatorname{dom} \phi\left(\cdot, x_{n}\right)}\left(\phi\left(y, x_{n}\right)-\phi(y, \bar{x})\right) \geq 0, \forall\left\{x_{n}\right\} \subset K: x_{n} \rightarrow \bar{x}(n \rightarrow \infty)$.

Then CGMVI $(N(F, E), g, \phi, K)$ is strongly LP well-posed if and only if it has a unique solution.

Proof. The necessity is obvious. For the sufficiency, suppose that $\operatorname{CGMVI}(N(F, E), g, \phi, K)$ has a unique solution $x^{*}$. If CGMVI $(N(F, E), g, \phi, K)$ is not strongly LP well-posed, then there exists a LP approximating sequence $\left\{x_{n}\right\} \subset K$ for $\operatorname{CGMVI}(N(F, E), g, \phi, K)$ such that $\left\{x_{n}\right\}$ is not strongly convergent to $x^{*}$. Thus, there exist $w_{n} \in X$ with $w_{n} \rightarrow 0$ and $0<\epsilon_{n} \rightarrow 0$ such that $g\left(x_{n}\right)+w_{n} \in K$, and there exist $u_{n} \in F\left(x_{n}\right)$ and $v_{n} \in E\left(x_{n}\right)$ such that

$$
\left\langle N\left(u_{n}, v_{n}\right), g\left(x_{n}\right)-y\right\rangle+\phi\left(g\left(x_{n}\right), x_{n}\right)-\phi\left(y, x_{n}\right) \leq \epsilon_{n}, \quad \forall y \in K, n \geq 1 .
$$

Let $\left\{x_{n_{i}}\right\}$ be any subsequence of $\left\{x_{n}\right\}$ such that $x_{n_{i}} \rightarrow \bar{x}$ as $i \rightarrow \infty$. Clearly $\bar{x} \in K$. Since $\left\{g\left(x_{n}\right)+\right.$ $\left.w_{n}\right\} \subset K$ and $g$ is continuous, we know that $g(\bar{x}) \in K$. So, it follows from (6.1), $\epsilon_{n} \rightarrow 0$ and conditions $(\mathrm{C} 1)-(\mathrm{C} 3)$ that

$$
\liminf _{i \rightarrow \infty}\left(\phi\left(g\left(x_{n_{i}}\right), x_{n_{i}}\right)-\phi\left(g\left(x_{n_{i}}\right), \bar{x}\right)\right) \geq \liminf _{i \rightarrow \infty} \inf _{y \in \operatorname{dom} \phi\left(\cdot, x_{n_{i}}\right)}\left(\phi\left(y, x_{n_{i}}\right)-\phi(y, \bar{x})\right) \geq 0,
$$

and

$$
\begin{aligned}
\liminf _{i \rightarrow \infty}\left\langle N\left(u_{n_{i}}, v_{n_{i}}\right), g\left(x_{n_{i}}\right)-y\right\rangle+\phi(g(\bar{x}), \bar{x})-\phi(y, \bar{x}) \\
\quad \leq \liminf _{i \rightarrow \infty}\left\langle N\left(u_{n_{i}}, v_{n_{i}}\right), g\left(x_{n_{i}}\right)-y\right\rangle+\liminf _{i \rightarrow \infty} \phi\left(g\left(x_{n_{i}}\right), \bar{x}\right) \\
\quad+\liminf _{i \rightarrow \infty}\left(\phi\left(g\left(x_{n_{i}}\right), x_{n_{i}}\right)-\phi\left(g\left(x_{n_{i}}\right), \bar{x}\right)\right)+\liminf _{i \rightarrow \infty}\left(-\phi\left(y, x_{n_{i}}\right)\right) \\
\leq \liminf _{i \rightarrow \infty}\left\{\left\langle N\left(u_{n_{i}}, v_{n_{i}}\right), g\left(x_{n_{i}}\right)-y\right\rangle+\phi\left(g\left(x_{n_{i}}\right), \bar{x}\right)+\phi\left(g\left(x_{n_{i}}\right), x_{n_{i}}\right)-\phi\left(g\left(x_{n_{i}}\right), \bar{x}\right)-\phi\left(y, x_{n_{i}}\right)\right\} \\
\quad=\liminf _{i \rightarrow \infty}\left\{\left\langle N\left(u_{n_{i}}, v_{n_{i}}\right)-y_{n_{i}}, g\left(x_{n_{i}}\right)-y\right\rangle+\phi\left(g\left(x_{n_{i}}\right), x_{n_{i}}\right)-\phi\left(y, x_{n_{i}}\right)\right\} \\
\leq \liminf _{i \rightarrow \infty} \epsilon_{n_{i}}=0 .
\end{aligned}
$$

Since $F$ and $E$ are nonempty compact-valued mappings, in terms of Lemma 2.1, for each $u_{n} \in$ $F\left(x_{n}\right)$ and $v_{n} \in E\left(x_{n}\right)$ there exist $\bar{u}_{n} \in F(\bar{x})$ and $\bar{v}_{n} \in E(\bar{x})$ such that $\left\|u_{n}-\bar{u}_{n}\right\| \leq \mathscr{H}\left(F\left(x_{n}\right), F(\bar{x})\right)$ and $\left\|v_{n}-\bar{v}_{n}\right\| \leq \mathscr{H}\left(E\left(x_{n}\right), E(\bar{x})\right)$. Since $F$ and $E$ both are $\mathscr{H}$-continuous, one deduces that $\left\|u_{n_{i}}-\bar{u}_{n_{i}}\right\| \leq \mathscr{H}\left(F\left(x_{n_{i}}\right), F(\bar{x})\right) \rightarrow 0$ and $\left\|v_{n_{i}}-\bar{v}_{n_{i}}\right\| \leq \mathscr{H}\left(E\left(x_{n_{i}}\right), E(\bar{x})\right) \rightarrow 0$ as $i \rightarrow \infty$. Since $F(\bar{x})$ and $E(\bar{x})$ both are compact, without loss of generality we may assume that $\bar{u}_{n_{i}} \rightarrow \bar{u} \in F(\bar{x})$ and $\bar{v}_{n_{i}} \rightarrow \bar{v} \in E(\bar{x})$ as $i \rightarrow \infty$. Thus, we conclude that

$$
\left\|u_{n_{i}}-\bar{u}\right\| \leq\left\|u_{n_{i}}-\bar{u}_{n_{i}}\right\|+\left\|\bar{u}_{n_{i}}-\bar{u}\right\| \rightarrow 0 \quad \text { as } i \rightarrow \infty \text {, }
$$

and

$$
\left\|v_{n_{i}}-\bar{v}\right\| \leq\left\|v_{n_{i}}-\bar{v}_{n_{i}}\right\|+\left\|\bar{v}_{n_{i}}-\bar{v}\right\| \rightarrow 0 \quad \text { as } i \rightarrow \infty .
$$

That is, $u_{n_{i}} \rightarrow \bar{u}$ and $v_{n_{i}} \rightarrow \bar{v}$ as $i \rightarrow \infty$. Note that $N$ is mixed Lipschitz continuous with respect to the first and second arguments. Hence there exists a pair of constants $\zeta, \xi>0$ such that

$$
\left\|N\left(u_{n_{i}}, v_{n_{i}}\right)-N(\bar{u}, \bar{v})\right\| \leq \zeta\left\|u_{n_{i}}-\bar{u}\right\|+\xi\left\|v_{n_{i}}-\bar{v}\right\| \rightarrow 0 \quad \text { as } i \rightarrow \infty \text {. }
$$


This together with $u_{n_{i}} \rightarrow \bar{u}$ and $v_{n_{i}} \rightarrow \bar{v}$, implies that $N\left(u_{n_{i}}, v_{n_{i}}\right) \rightarrow N(\bar{u}, \bar{v})$ as $i \rightarrow \infty$. So, it immediately follows from (6.2) that

$$
\langle N(\bar{u}, \bar{v}), g(\bar{x})-y\rangle+\phi(g(\bar{x}), \bar{x})-\phi(y, \bar{x}) \leq 0, \quad \forall y \in K .
$$

Thus, $\bar{x}$ solves CGMVI $(N(F, E), g, \phi, K)$. Since CGMVI $(N(F, E), g, \phi, K)$ has a unique solution $x^{*}$, we get $\bar{x}=x^{*}$. So, $x_{n} \rightarrow x^{*}$ as $n \rightarrow \infty$. This leads to a contradiction. Therefore, $\operatorname{CGMVI}(N(F, E), g, \phi, K)$ is strongly LP well-posed. The proof is complete.

Let $K \subset X$ and $g: X \rightarrow X$ be a mapping. Now, for any $\delta_{0} \geq 0$, we denote $M_{g}\left(\delta_{0}\right)=\{x \in X$ : $\left.d(g(x), K) \leq \delta_{0}\right\}$. We have the following result.

Theorem 6.2. Let $K$ be a nonempty, closed and convex subset of $X$. Let $F, E: X \rightarrow 2^{X^{*}}$ be nonempty compact-valued mappings which both are upper semicontinuous. Let $g: X \rightarrow X$ be a continuous mapping and $N: X^{*} \times X^{*} \rightarrow X^{*}$ be mixed Lipschitz continuous with respect to the first and second arguments. Assume that $\phi: X \times X \rightarrow \mathbf{R} \cup\{+\infty\}$ satisfies the conditions:

(C1) $\phi$ is proper, convex and lower semicontinuous in the first argument;

(C2) $\phi$ is upper semicontinuous in the second argument;

(C3) $\liminf _{n \rightarrow \infty} \inf _{y \in \operatorname{dom} \phi\left(\cdot, x_{n}\right)}\left(\phi\left(y, x_{n}\right)-\phi(y, \bar{x})\right) \geq 0, \forall\left\{x_{n}\right\} \subset K: x_{n} \rightarrow \bar{x}(n \rightarrow \infty)$.

If there exists some $\delta_{0}>0$ such that $M\left(\delta_{0}\right)$ is compact, then $\operatorname{CGMVI}(N(F, E), g, \phi, K)$ is strongly LP $\alpha$-well-posed in the generalized sense.

Proof. Let $\left\{x_{n}\right\} \subset K$ be a LP $\alpha$-approximating sequence for CGMVI $(N(F, E), g, \phi, K)$. Then there exist $0<\epsilon_{n}^{\prime} \rightarrow 0$ and $w_{n} \in X$ with $w_{n} \rightarrow 0$ such that

$$
g\left(x_{n}\right)+w_{n} \in K
$$

and there exist $u_{n} \in F\left(x_{n}\right)$ and $v_{n} \in E\left(x_{n}\right)$ satisfying

$$
\left\langle N\left(u_{n}, v_{n}\right), g\left(x_{n}\right)-y\right\rangle+\phi\left(g\left(x_{n}\right), x_{n}\right)-\phi\left(y, x_{n}\right) \leq \frac{\alpha}{2}\left\|g\left(x_{n}\right)-y\right\|^{2}+\epsilon_{n}^{\prime}, \quad \forall y \in K, n \geq 1 .
$$

Since $g\left(x_{n}\right)+w_{n} \in K$, then there exists $k_{n} \in K$ such that $g\left(x_{n}\right)+w_{n}=k_{n}$. Thus,

$$
d\left(g\left(x_{n}\right), K\right) \leq\left\|g\left(x_{n}\right)-k_{n}\right\|=\left\|w_{n}\right\| \rightarrow 0 .
$$

Setting $\epsilon_{n}=\max \left\{\epsilon_{n}^{\prime},\left\|w_{n}\right\|\right\}$, we can get $d\left(g\left(x_{n}\right), K\right) \leq \epsilon_{n}$. Without loss of generality, we may assume that $\left\{x_{n}\right\} \subset M\left(\delta_{0}\right)$ for $n$ sufficiently large. By the compactness of $M\left(\delta_{0}\right)$, there exists a subsequence $\left\{x_{n_{i}}\right\}$ of $\left\{x_{n}\right\}$ and $\bar{x} \in M_{g}\left(\delta_{0}\right)$ such that $x_{n_{i}} \rightarrow \bar{x}$ as $i \rightarrow \infty$. It is easy to see $\bar{x} \in K$. Furthermore, by the u.s.c. of $F$ and $E$ at $\bar{x}$ and compactness of $F(\bar{x})$ and $E(\bar{x})$, there exist a subsequence $\left\{\left(u_{n_{i}}, v_{n_{i}}\right)\right\}$ of $\left\{\left(u_{n}, v_{n}\right)\right\}$ some $(\bar{u}, \bar{v}) \in F(\bar{x}) \times E(\bar{x})$ such that $u_{n_{i}} \rightarrow \bar{u}$ and $v_{n_{i}} \rightarrow \bar{v}$. Since $N$ is mixed Lipschitz continuous with respect to the first and second arguments, there exists a pair of constants $\zeta, \xi>0$ such that as $i \rightarrow \infty$,

$$
\left\|N\left(u_{n_{i}}, v_{n_{i}}\right)-N(\bar{u}, \bar{v})\right\| \leq \zeta\left\|u_{n_{i}}-\bar{u}\right\|+\xi\left\|v_{n_{i}}-\bar{v}\right\| \rightarrow 0 .
$$


Since $\phi$ satisfies conditions (C1) $-(\mathrm{C} 3)$, from (6.3) we deduce that for all $y \in K$,

$$
\begin{aligned}
& \langle N(\bar{u}, \bar{v}), g(\bar{x})-y\rangle+\phi(g(\bar{x}), \bar{x})-\phi(y, \bar{x}) \\
& \leq \liminf _{i \rightarrow \infty}\left\langle N\left(u_{n_{i}}, v_{n_{i}}\right), g\left(x_{n_{i}}\right)-y\right\rangle+\liminf _{i \rightarrow \infty} \phi\left(g\left(x_{n_{i}}\right), \bar{x}\right) \\
& \quad+\liminf _{i \rightarrow \infty}\left(\phi\left(g\left(x_{n_{i}}\right), x_{n_{i}}\right)-\phi\left(g\left(x_{n_{i}}\right), \bar{x}\right)\right)+\liminf _{i \rightarrow \infty}\left(-\phi\left(y, x_{n_{i}}\right)\right) \\
& \left.\leq \liminf _{i \rightarrow \infty}\left\langle N\left(u_{n_{i}}, v_{n_{i}}\right), g\left(x_{n_{i}}\right)-y\right\rangle+\phi\left(g\left(x_{n_{i}}\right), \bar{x}\right)+\phi\left(g\left(x_{n_{i}}\right), x_{n_{i}}\right)-\phi\left(g\left(x_{n_{i}}\right), \bar{x}\right)-\phi\left(y, x_{n_{i}}\right)\right\} \\
& =\liminf _{i \rightarrow \infty}\left\{\left\langle N\left(u_{n_{i}}, v_{n_{i}}\right), g\left(x_{n_{i}}\right)-y\right\rangle+\phi\left(g\left(x_{n_{i}}\right), x_{n_{i}}\right)-\phi\left(y, x_{n_{i}}\right)\right\} \\
& \leq \liminf _{i \rightarrow \infty}\left\{\frac{\alpha}{2}\left\|g\left(x_{n_{i}}\right)-y\right\|^{2}+\epsilon_{n_{i}}^{\prime}\right\} \\
& =\frac{\alpha}{2}\|g(\bar{x})-y\|^{2},
\end{aligned}
$$

That is,

$$
\langle N(\bar{u}, \bar{v}), g(\bar{x})-y\rangle+\phi(g(\bar{x}), \bar{x})-\phi(y, \bar{x}) \leq \frac{\alpha}{2}\|g(\bar{x})-y\|^{2}, \quad \forall y \in K .
$$

For any $y \in K$, put $y_{t}=g(\bar{x})+t(y-g(\bar{x}))$ for all $t \in(0,1)$, it is easy to see $y_{t} \in K$. Now, utilizing (6.4), one has

$$
\left\langle N(\bar{u}, \bar{v}), g(\bar{x})-y_{t}\right\rangle+\phi(g(\bar{x}), \bar{x})-\phi\left(y_{t}, \bar{x}\right) \leq \frac{\alpha}{2}\left\|g(\bar{x})-y_{t}\right\|^{2} .
$$

By the convexity of $\phi$ in the first argument, we conclude that for each $t \in(0,1)$, one has

$$
\langle N(\bar{u}, \bar{v}), g(\bar{x})-y\rangle+\phi(g(\bar{x}), \bar{x})-\phi(y, \bar{x}) \leq \frac{\alpha t}{2}\|g(\bar{x})-y\|^{2}, \quad \forall y \in K .
$$

Letting $t \rightarrow 0^{+}$in the last inequality, we have

$$
\langle N(\bar{u}, \bar{v}), g(\bar{x})-y\rangle+\phi(g(\bar{x}), \bar{x})-\phi(y, \bar{x}) \leq 0, \quad \forall y \in K .
$$

This shows that $\bar{x}$ solves CGMVI $(N(F, E), g, \phi, K)$. Thus, CGMVI $(N(F, E), g, \phi, K)$ is strongly LP $\alpha$-well-posed in the generalized sense. The proof is complete.

Remark 6.1. Our Theorems 6.1-6.2 improve, extend and develop Theorems 6.1-6.2 in [19] to a great extent because our $\operatorname{CGMVI}(N(F, E), g, \phi, K)$ is more general than the $\operatorname{GMVI}(F, \phi, K)$ in [19].

\section{References}

[1] A. N. Tykhonov, On the stability of the functional optimization problem, USSR J. Comput. Math. Phys., 6 (1966), 631-634.

[2] T. Zolezzi, Extend well-posedness of optimization problems, J. Optim. Theory Appl., 91 (1996), 257-266.

[3] T. Zolezzi, Well-posedness criteria in optimization with application to the calculus of variations, Nonlinear Anal. TMA, 25 (1995), 437-453.

[4] T. Zolezzi, Well-posedness of optimal control problems, Control Cybernet., 23 (1994), 289-301. 
[5] E. S. Levitin and B. T. Polyak, Convergence of minimizing sequences in conditional extremum problem, Soviet Math. Dokl., 7 (1966), 764-767.

[6] E. M. Bednarczuk, Well-Posedness of Optimization Problem, in: J. Jahn, W. Krabs (Eds.), Recent Advances and Historical Development of Vector Optimization Problems, in: Lecture Notes in Economics and Mathematical Systems, vol. 294, Springer, Berlin, 1987, 51-61.

[7] R. Lucchetti and F. Patrone, A characterization of Tykhonov well-posedness for minimum problems with applications to variational inequalities, Numer. Funct. Anal. Optim., 3 (1981), (4), 461-476.

[8] R. Lucchetti and F. Patrone, Hadamard and Tykhonov well-posedness of certain class of convex functions, J. Math. Anal. Appl., 88 (1982), 204-215.

[9] L. C. Ceng, J. C. Yao, Well-posedness of generalized mixed variational inequalities, inclusion problems and fixed-point problems, Nonlinear Anal. TMA, 69 (2008), 4585-4603.

[10] Y. P. Fang, N. J. Huang and J. C. Yao, Well-posedness by perturbations of mixed variational inequalities in Banach spaces, European J. Oper. Res., 201 (2010), 682-692.

[11] Y. P. Fang, N. J. Huang and J. C. Yao, Well-posedness of mixed variational inequalities, inclusion problems and fixed-point problems, J. Global Optim., 41 (2008), 117-133.

[12] B. Lemaire, Well-posedness, conditions, and regularization of minimization, inclusion, and fixed-point problems, Pliska Stud. Math. Bulgar., 12 (1998), 71-84.

[13] B. Lemaire, C. Ould Ahmed Salem and J. P. Revalski, Well-posedness by perturbations of variational problems, J. Optim. Theory Appl., 115 (2002), 345-368.

[14] R. Hu and Y. P. Fang, Levitin-Polyak well-posedness of variational inequalities, Nonlinear Anal. TMA, 72 (2010), 373-381.

[15] K. Kuratowski, Topology, vols. 1-2, Academic Press, New York, NY, USA, 1968.

[16] F. H. Clarke, Optimization and Nonsmooth Analysis, in: Classics in Applied Mathematics, SIAM, Philadelphia, 1990.

[17] I. Ekeland and R. Temma, Convex Analysis and Variational Problems, in: Studies in Mathematics and Applications, North-Holland, Amsterdam, 1976.

[18] Z. B. Xu and G. F. Roach, On the uniform continuity of metric projections in Banach spaces, J. Approx. Theory Appl., 8 (1992), (3), 11-20.

[19] X. B. Li and F. Q. Xia, Levitin-Polyak well-posedness of a generalized mixed variational inequality in Banach spaces, Nonlinear Anal. TMA, 75 (2012), 2139-2153.

[20] X. X. Huang, X. Q. Yang and D. L. Zhu, Levitin-Polyak well-posedness of variational inequality problems with functional constraints, J. Global Optim., 44 (2009), (2), 159-174.

[21] Y. B. Xiao and N. J. Huang, Well-posedness for a class of variational-hemivariational inequalities with perturbations, J. Optim. Theory Appl., 151 (2011), 33-51.

[22] L. C. Ceng, N. Hadjisavvas, S. Schaible and J. C. Yao, Well-posedness for mixed quasivariational-like inequalities, J. Optim. Theory Appl., 139 (2008), 109-125.

[23] L. C. Ceng, H. Gupta and C. F. Wen, Well-posedness by perturbations of variational-hemivariational inequalities with perturbations, Filomat, 26(2012), 881-895.

[24] L. C. Ceng, N. C. Wang and J. C. Yao, Well-posedness for a class of strongly mixed variational-hemivariational inequalities with perturbations, J. Appl. Math. (2012) Art. ID 712306, 21 pp.

Department of Mathematics, Shanghai Normal University, Shanghai 200234, China.

E-mail: zenglc@hotmail.com

Center for Fundamental Science, and Research Center for Nonlinear Analysis and Optimization, Kaohsiung Medical University, Kaohsiung 807, Taiwan.

E-mail: cfwen@kmu.edu.tw 